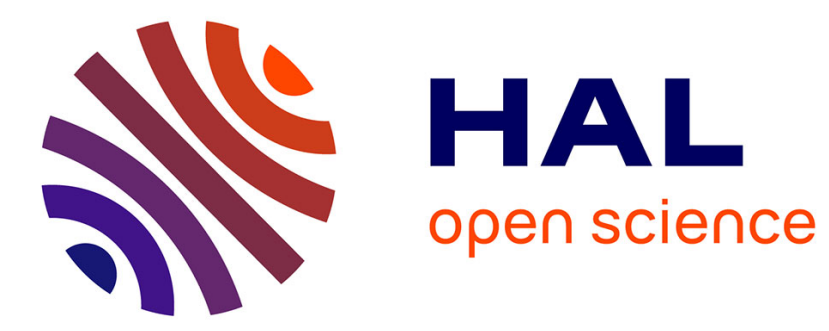

\title{
SERPING1 mutation update: Mutation spectrum and C1 Inhibitor phenotypes
}

Denise Ponard, Christine Gaboriaud, Delphine Charignon, Arije Ghannam, Ineke Wagenaar-Bos, Dorina Roem, Alberto López-Lera, Margarita López-Trascasa, Mario Tosi, Christian Drouet

\section{To cite this version:}

Denise Ponard, Christine Gaboriaud, Delphine Charignon, Arije Ghannam, Ineke Wagenaar-Bos, et al.. SERPING1 mutation update: Mutation spectrum and $\mathrm{C} 1$ Inhibitor phenotypes. Human Mutation, 2020, 41 (1), pp.38-57. 10.1002/humu.23917 . hal-02429966

\section{HAL Id: hal-02429966 https://hal.science/hal-02429966}

Submitted on 24 Sep 2020

HAL is a multi-disciplinary open access archive for the deposit and dissemination of scientific research documents, whether they are published or not. The documents may come from teaching and research institutions in France or abroad, or from public or private research centers.
L'archive ouverte pluridisciplinaire HAL, est destinée au dépôt et à la diffusion de documents scientifiques de niveau recherche, publiés ou non, émanant des établissements d'enseignement et de recherche français ou étrangers, des laboratoires publics ou privés. 
Christian DROUET ORCID iD: 0000-0003-1318-4278

\section{Title}

\section{SERPING1 mutation update: Mutation spectrum and C1 Inhibitor phenotypes}

\section{Running title}

Description and phenotype analysis of SERPING1 variants

\section{Authors}

Denise Ponard $^{1,2}$, Christine Gaboriaud ${ }^{3}$, Delphine Charignon ${ }^{4,5}$, Arije Ghannam ${ }^{4,5}$, Ineke G.A. Wagenaar-Bos ${ }^{6,7}$, Dorina Roem ${ }^{6}$, Alberto López-Lera ${ }^{8}$, Margarita LópezTrascasa $^{8,9}$, Mario Tosi ${ }^{10}$, Christian Drouet ${ }^{1,4,11}$

\section{Author affiliations}

${ }^{1}$ Centre de Référence des Angioedèmes (CREAK), Filière MaRIH, CHU Grenoble France

${ }^{2}$ Laboratoire d’Immunologie, CHU Grenoble Alpes, Grenoble, France

${ }^{3}$ Univ. Grenoble Alpes, CEA, CNRS, IBS, Grenoble, France

${ }^{4}$ Univ. Grenoble Alpes, GREPI EA7408 and EFS Rhône-Alpes, Grenoble, France

This article has been accepted for publication and undergone full peer review but has not been through the copyediting, typesetting, pagination and proofreading process, which may lead to differences between this version and the Version of Record. Please cite this article as doi: 10.1002/humu.23917.

This article is protected by copyright. All rights reserved. 
${ }^{5}$ KininX SAS, Grenoble, France

${ }^{6}$ Department of Immunopathology, Sanquin Research, Amsterdam, the Netherlands

${ }^{7}$ University of Twente, Enschede, the Netherlands

8 Biomedical Research Network on Rare Diseases (CIBERER)-U754, Instituto de Investigación Hospital Universitario La Paz (IdiPAZ), Madrid, Spain

${ }^{9}$ Universidad Autónoma de Madrid, Madrid, Spain

${ }^{10}$ Inserm U1245, University of Rouen, Rouen, France

11 Université Paris-Descartes, Inserm U1016, CNRS UMR8104, Institut Cochin, Paris, France

\section{Corresponding author}

Denise Ponard, CHU Grenoble, CS10217, F-38043 Grenoble France; Phone: +33 476 767201 Email denise.ponard@gmail.com

\section{Conflict of Interest}

DC and AG received funding from KininX. All the other authors declare no conflict of interest. ALL has received educational and advisory fees from Shire.

\section{ORCID}

Delphine Charignon https://orcid.org/0000-0003-3423-0608

Christian Drouet http://orcid.org/0000-0003-1318-4278

This article is protected by copyright. All rights reserved. 
Christine Gaboriaud http://orcid.org/0000-0001-5308-0516

Arije Ghannam https://orcid.org/0000-0002-5045-0566

Alberto López Lera https://orcid.org/0000-0002-9596-6910

Margarita López-Trascasa https://orcid.org/0000-0001-8594-282X

Ineke Wagenaar-Bos https://orcid.org/0000-0002-0312-0863

\title{
DATA SHARING STATEMENT
}

Repository of novel variants. Novel variants $(n=120)$ have been successfully introduced at Global Variome shared LOVD; URL https://databases.lovd.nl/shared/individuals/SERPING1.

Abbreviations: C1Inh, C1 Inhibitor; C1-INH-HAE, HAE with C1Inh deficiency; EQT, exon quantitation technique; ESE, exonic splicing enhancers; ESS, exonic splicing silencers; HAE, hereditary angioedema; HAE-I/HAE-II/HAE-intermediate, HAE type I/type II/intermediate type; ISE, intronic splicing enhancers; ISS, intronic splicing silencers; KKS, kallikrein-kinin system; RCL, reactive centre loop; UTR, untranslated.

\begin{abstract}
C1 Inhibitor (C1Inh) deficiency is responsible for hereditary angioedema (C1-INH-HAE) and caused by variants of the SERPING1/C1INH/C1NH gene. C1Inh is the major control of kallikrein-kinin system. C1Inh deficiency leads to its uncontrolled activation, with subsequent generation of the vasoactive peptide bradykinin. This update documents 748
\end{abstract}

This article is protected by copyright. All rights reserved. 
different SERPING1 variants, including published variants and additional 120 unpublished ones. They were identified as heterozygous variants $(\mathrm{n}=729)$, as homozygous variants in 10 probands) and as compound heterozygous variants (9 combinations). Six probands with heterozygous variants exhibited gonadal mosaicism. Probands with heterozygous ( $n=72)$ and homozygous $(n=1)$ variants were identified as de novo cases. Overall, 58 variants were found at positions showing high residue conservation among serpins, and have been referred to as a mousetrap function of C1Inh: reactive centre loop, gate, shutter, breach, and hinge. C1Inh phenotype analysis identified dysfunctional serpin variants with failed serpin-protease association and a residual 105-kDa species after incubation with target protease. Regarding this characteristic, in conditions with low antigenic C1Inh, 74 C1-INH-HAE probands presented with an additional so-called intermediate C1-INH-HAE phenotype. The present update addresses a comprehensive SERPING1 variant spectrum that facilitates genotype-phenotype correlations, highlighting residues of strategic importance for serpin function and for identification of C1Inh deficiency as serpinopathy.

Key words: C1 Inhibitor; SERPING1; mutational spectrum; hereditary angioedema; protease control; serpin; serpinopathy; structure-function relationship

\section{BACKGROUND}

C1 Inhibitor (C1Inh) is a multi-functional Serine protease inhibitor (serpin) that controls various Serine proteases in multiple plasmatic cascades, eg. contact phase, thereby limiting the production of the vasoactive peptide bradykinin [Davis et al., 2010]. C1Inh deficiency is responsible for hereditary angioedema (C1-INH-HAE). Today, C1-INH-

This article is protected by copyright. All rights reserved. 
HAE is considered a heterogeneous disorder with a complex pathophysiology [Hofman et al., 2016]. Genetic defects of C1-INH-HAE patients have been recognized in the SERPING1 gene, encoding C1Inh and located at 11q12-q13.1 in humans; pathogenic variants usually behaved in an autosomal-dominant character with incomplete penetrance and an uncertain prevalence estimated at 1:50,000. Haploinsufficiency can occur through a number of ways; some rare variants, eg. those found with as homozygous variants or as compound heterozygous variants may be quantitatively too weak to cause haploinsufficiency, are illustrated in section 4.1 with an example. In addition, SERPING1 alleles affecting secretion of wild-type C1Inh protein in a dominant negative fashion are also introduced in section4.1. In the original description of SERPING1 gene defects, the variants have been distributed in a type 1 (HAE-I) where "C1-INH-HAE appears to result from failure to synthesize the esterase inhibitor", and a type 2 (HAE-II), where "an abnormal, non-functional protein is synthesized” [Rosen et al., 1965]. These defects consisted of deletions/duplications [Stoppa-Lyonnet et al., 1987] and other variants [Agostoni et al., 2004; Maurer et al., 2018], and this genetic disease has been referred to as HAE due to C1Inh deficiency, ie. C1-INH-HAE, with MIM \#606860. Affected patients presented with non-pruritic, subcutaneous, and submucosal episodes of localized swelling in the extremities, face, gut, or upper airways. Laryngeal oedema caused by upper respiratory mucosal involvement may lead to asphyxia [Agostoni et al., 2004]. Reduced plasma levels of C1Inh lead to enhanced activation of the kallikrein-kinin system (KKS) triggering accumulation of kinins and increased vascular permeability. Recent biological testing performed on C1-INH-HAE patients has suggested that C1Inh deficiency affects KKS control, more than that of C1 activation [Charignon et al., 2017].

This article is protected by copyright. All rights reserved. 
C1Inh is a single-chain, highly glycosylated circulating protein of $\mathrm{Mr}$ 105kDa (Figure 1A). As a serpin (clade G), it regulates Serine proteases via an irreversible suicide substrate mechanism [Lomas et al., 2005]. Serpins are highly conserved proteins, with the serpin domain comprising three $\beta$-sheets (A-C) and nine $\alpha$-helices (Figure 1B-E). By analogy with the archetypal serpin $\alpha 1$-antitrypsin (A1AT), the reactive site is identified by a peptide bond between positions referred to as P1-P1' and is located in an exposed, flexible loop (RCL). C1Inh RCL extends from P15 to P5', with P15-P1 representing the affinity-based insertion sequence as strand 4A (s4A) into the central $\beta$-sheet A [Bos et al., 2002]. Serpins are unique in that the native molecule is not the most stable form, but a kinetically trapped intermediate [Patston et al., 1995]. Besides the native and cleaved forms, serpins can adopt additional, more stable conformations that have been shown to be biologically relevant. One of these is a latent, inactive form, adopted naturally by plasminogen activator inhibitor-1 and antithrombin-III, in which the uncleaved RCL is inserted into $\beta$-sheet $\mathrm{A}$ as s4A, and the C-terminal peptide stalk and s1C are reoriented along the side of the molecule, as shown for latent C1Inh [Beinrohr et al., 2007] (Figures 1C, -E). Multimeric conformations have also been identified in certain naturally occurring variants affecting the C1Inh mobile domains [Eldering et al., 1995; Madsen et al., 2014; Haslund et al., 2019]. Such variants render the molecule vulnerable to retention within the biosynthesis cell compartment, a hallmark of serpinopathies [Lomas et al., 2005]. SERPING1 variant investigation has revealed several key genetic features, which have recently been reviewed [Germenis \& Speletas, 2016]. More than 500 distinct variants are listed in the Human Gene Mutation Database (HGMD ${ }^{\circledR}$; http://www.hgmd.cf.ac.uk/;

This article is protected by copyright. All rights reserved. 
survey on $18^{\text {th }}$ Feb 2018) [Stenson et al., 2017]. A C1Inh-specific mutational database of the SERPING1 locus, with updated reports, has been described [Kalmár et al., 2005].

In this mutation update, we selected the peer-reviewed articles and $\mathrm{HGMD}^{\circledR}$ as base for known variants and documented 120 previously unpublished variants for reviewing the current state of our knowledge of pathogenic or likely pathogenic SERPING1 variants. We also discuss variant positions of strategic importance in structure-function relationships in the ongoing international efforts toward the recognition of C1Inh deficiency as a conformational disease.

\section{METHODS}

SERPING1 variant extraction

All of the variants of SERPING1 reported in peer-reviewed articles, locus-specific HAEdb (URL http://hae.biomembrane.hu/) or HGMD $^{\circledR}$ and identified in subjects ascertained on the basis of a C1-INH-HAE diagnostic were included in the update. SERPING1 genotypes were recorded from the original publications and adjustment of nomenclature of certain variations was made to ascertain that base pair and predicted protein sequence numbering were based on the SERPING1 reference sequence NCBI \#NM_000062.2 that should be taken for any variant with prefix “c.”.

Subjects

Unrelated C1-INH-HAE patients $(\mathrm{n}=379)$, who met the international consensus Criteria [Maurer et al., 2018], were enrolled and subjected to molecular analysis of the SERPING1 gene. Each diagnosis of C1-INH-HAE was supported by two separated This article is protected by copyright. All rights reserved. 
determinations of C1Inh functional levels [Drouet et al., 1988], which were mainly below $30 \%$ of the target value of a reference population. Reference values have been obtained from samples harvested from healthy blood donors (Etablissement Français du Sang, Grenoble France).

Biological testing

Antigenic C1Inh was quantified using nephelometry (BNII; Siemens Healthcare Diagnostics, Marburg, Germany); C1Inh function was measured using a chromogenic assay with C1s protease [Drouet et al., 1988] or contact-phase proteins as targets [Ghannam et al., 2015]. Anti-C1Inh immunoblot was performed on 7.5\% SDS-PAGE under non-reducing conditions.

\section{Genotyping}

From samples of patients enrolled in the study, genomic DNA was isolated using a guanidine method, the MagNA Pure ${ }^{\circledR}$ System (Roche Life Science, Meylan, France), or the NucleoSpin Blood $^{\circledR}$ kit (Macherey-Nagel, Düren, Germany) on a JANUS ${ }^{\circledR}$ Workstation (PerkinElmer). For variant analysis, the promoter sequence, the noncoding exon 1, as well as the 7 coding exons and intron-exon boundaries of the SERPING1 gene (NCBI \#NM_000062.2) were amplified from genomic DNA. Amplicons were then subjected to direct automated sequencing on an Applied Biosystems $3130^{\circledR}$ DNA Analyser (Life Technologies, Carlsbad, CA, USA). In cases of negative screening by Sanger, multiplex ligation-dependent probe amplification (MLPA) was subsequently performed to analyse genomic rearrangements using the SALSA MLPA P243 ${ }^{\circledR}$ SerpinG1 kit and data were analysed using the COFFALYSER ${ }^{\circledR}$ software (MRC-Holland, This article is protected by copyright. All rights reserved. 
Amsterdam, NL). Genomic deletion of isolated or joint exons was confirmed by longrange PCR from the flanking exons using the Takara-LA DNA polymerase (Takara Bio Inc., Otsu, Shiga, Japan) and analysis of the amplification products on $0.8 \%$ agarose gel. SERPING1 variations were numbered starting from the first nucleotide of the initiation Methionine of the cDNA sequence (NCBI \#NM_000062.2) according to the Human Genome Variation Society guidelines. For amino acid positions and, as is usual for serpins, we used historical numbering based on the 478-residue mature protein (without the $22 \mathrm{~N}$-terminal residues of the signal peptide). For genomic positioning, the base assignment defined by Carter et al. [1991] was mentioned in order to enable comparisons with other nomenclatures for SERPING1 (see the database HAEdb).

\section{Human Gene Mutation Database (HGMD $\left.{ }^{\circledR}\right)$}

Identified SERPING1 variants have been collected from the on-line HGMD ${ }^{\circledR}$, with additional unregistered variants, personal identifications and recent descriptions.

\section{Bioinformatics}

Bioinformatic analysis of all SERPING1 missense variants identified in the probands we studied and of variants reported to $\mathrm{HGMD}^{\circledR}$ was performed using three different software packages: SIFT ${ }^{\circledR}$ (Sorting Intolerant From Tolerant; URL sift.bii.a-star.edu.sg/; [Sim et al. 2012]), $\quad$ PolyPhen $2^{\circledR} \quad$ (Polymorphism $\quad$ Phenotyping $\quad$ v2; $\quad$ URL genetics.bwh.harvard.edu/pph2/; [Adzhubei et al. 2013]) and MutationTaster ${ }^{\circledR}$ (URL mutationtaster.org; [Schwartz et al. 2014]). For determining Minor Allele Frequency (MAF) of some variants, we used the Genome Aggregation Database v2.1.1, acronym gnomAD (http://gnomad.broadinstitute.org/gene/ENSG00000149131).

This article is protected by copyright. All rights reserved. 
Ethics

All procedures were performed in accordance with the principles of the Helsinki declaration and French ethical policies governing the use of biological sample collections (Ministry of Health declaration DC-2008-634). Informed written consent for molecular genetic analysis was obtained from patients. In addition, the last-enrolled patients provided their informed consent to participating in the investigation with biological assays, and blood donors (healthy controls) answered the standard questionnaire. The Grenoble University Hospital’s Institutional Review Board (South-East committee V) stated that the supporting programs, sample collection and processing methods fulfilled the requirements. All the data were processed anonymously.

\section{VARIANTS OF SERPING1 IN C1-INHIBITOR DEFICIENCY}

\subsection{The spectrum of SERPING1 variants causing C1-INH-HAE}

Supplementary material displays the SERPING1 alterations that were found in the $\mathrm{HGMD}^{\circledR}$ tables and the published reports and that we have observed in probands. As shown on Figure 2, the overall SERPING1 variants comprise missense variants (n = 241; 32.1\%) and nonsense variants $(\mathrm{n}=66 ; 9.0 \%)$, compiled in Supp. Table S1, short deletions, duplications and delins variants ( $\mathrm{n}=272$; 36.2\%; Supp. Table S2), splice defects ( $n=100 ; 13.6 \%$; Supp. Table S3), large deletions and duplications $(n=62 ; 8.2 \%$; Supp. Table S4) and a few variants affecting 5' untranscribed and 3' UTR sequences (n = 7; 0.9\%; Supp. Table S5), amounting to a total of 748 distinct variants and including 120 novel variants. The latter and recurrent variants have been identified in 379 pedigrees that we investigated in the present study. The mature C1Inh N-terminal domain (residues 1This article is protected by copyright. All rights reserved. 
112; Figure 1A) displayed nine missense variants (9/241; 3.7\%), while its serpin domain (residues 113-478) presented almost all missense variants (232/241; 96.3\%). This variant distribution was in a close relationship with C1Inh domains, with the few missense variants considered as disease-causing suggesting a non-functional $\mathrm{N}$-terminal domain that is specific to C1Inh among serpins. This is in line with the independent biological properties of both domains. Overall, ten homozygous deficient probands were recorded, all but one were symptomatic, five with a missense variant, two with a splicing defect and one with a delins variant (Supp Table S7). Compound heterozygosity has been found in 9 pedigrees. Gonadal mosaicism has been reported in 6 probands and two young brothers were severely affected with asymptomatic parents [Guarino et al., 2006]. Probably these cases are underestimated because of non-systematically investigated. Overall, 73 C1Inh deficient probands presented with a de novo variant, ie. in a patient with the disease and no family history, with an absence of pathogenic variant detected in both parental DNA samples. As suggested by the repetitive occurrence of variant reports (Supp. Tables S1-3), some positions/regions of SERPING1 gene could represent hotspots of gene alteration; of particular interest are the codons 1, 184, 271 to 272, 466 and 494.

Missense variants. In every case when it has been reported, a genetic variant was connected to a biological phenotype: serpin function of C1Inh, circulating species. While identified in relation to HAE-II phenotypes, the c.1198C>T;p.(Arg378Cys)/(Arg400Cys) mutant has been proved hypomorphic because of a tight control exerted over C1s protease, with a decrease in the constant of inhibition of $\approx 25 \%$, more than over contactphase activation, with $\approx 45 \%$ [López-Lera et al., 2010; Ghannam et al., 2015], and a remittent serpin function [Caccia et al., 2018]. The $\operatorname{Arg}^{378}$ position was also recognised as This article is protected by copyright. All rights reserved. 
being involved in the polyanion potentiation of C1Inh function (Figures 1B, -D; Tables 1, -2). These observations are in line with control of C1s protease by polyanions, but not of factor XIIa or kallikrein [Wuillemin et al., 1996]. Conversely the c.452T>G;p.(Leu129Arg)/(p.Leu151Arg) has retained control of contact phase [Ghannam et al., 2015]. Glycosylation positions were disrupted at only three positions: $\mathrm{Thr}^{54}$, with c.227C >T;p.(Thr54Ile)/(Thr76Ile), $\quad \mathrm{Asn}^{250}, \quad$ with c.814_816delAAC;p.(Asn250del)/(Asn272del) and c.814_816dupAAC;p.(Asn250dup)/(Asn272dup) and $\mathrm{Asn}^{330}$, with c.1055A>T;p.(Asn330Ile)(/Asn352Ile). Glycosylation at the latter position has been found of strategic importance, as removal of the oligosaccharide resulted in a dramatic decrease of the expression yield [Rossi et al, 2010]. Missense variants were analysed so as to predict protein structure folding by means of three different bioinformatic methods $\left(\mathrm{SIFT}^{\circledR}\right.$, PolyPhen $2^{\circledR}$, and MutationTaster $\left.{ }^{\circledR}\right)$. Conflicts between bioinformatics prediction methods are observed for some variants, eg. c.467C>A;p.(Ala134Asp)/(Ala156Asp), c.568A>G;p.(Lys168Glu)/(Lys190Glu), $\quad$ c.722C>G;p.(Arg219Pro)/(Arg241Pro), c.785T>C;p.(Ile240Thr)/(Ile262Thr) and c.1198C>T;p.(Arg378Cys)/(Arg400Cys), that were found to be either tolerant ( $\operatorname{SIFT}^{\circledR}$ ), probably damaging $\left(\right.$ PolyPhen $2^{\circledR}$ ), and disease causing (MutationTaster ${ }^{\circledR}$ ), or vice-versa, for protein function and disease-causing predictions (Supp. Table S1). In addition to C1Inh variants associated with a loss of protease targeting, recurrent variants that have been established as disease-causing for years [c.1396C>A;p.(Arg444Ser)/(Arg466Ser), c.1397G>A;p.(Arg444His)/(Arg466His), and 1396C>G;p.(Arg444Gly)/(Arg466Gly)] were identified as tolerant or benign, because its cleavage-site property is not taken into account (Table 1). Analysis using

This article is protected by copyright. All rights reserved. 
MutationTaster $^{\circledR}$ attributed some HAE-II variants to polymorphisms, with affected pedigrees developing severe clinical phenotypes and patients presenting with C1Inh function below $30 \%$ of the target value. This apparent discrepancy could be pertaining to additional factors modifying clinical and biological phenotypes. The variants involved are c.1319C>T, p.(Ala440Val)/(Ala418Val); c.1378T>C， p.(Ser460Pro)/(Ser438Pro) and c.1399A>C, p.(Thr467Pro)/(Thr445Pro). However, distinguishing possibly harmless, non-pathogenic variants from bona-fide disease-causing ones by means of bioinformatic analyses alone might not be accurate enough to predict effects of these variants on serpin function.

Splicing defects. Variants affecting splice sites and those in splicing regulatory elements, incl enhancers and silencers, can impair pre-mRNA splicing, eventually leading to a severe phenotype, as suggested by Grodecká et al. [2017]. SERPING1 is a naturally alternatively spliced gene, with in particular a highly variable abundance and a subtle regulation of exon 3 skipping [de la Cruz et al., 2012; Grymová et al., 2019]. Despite the availability of many prediction tools, prognosis of splicing affection is not trivial, especially when regulatory elements are involved. The presence of splicing defects was confirmed by exon skipping in 24 of non-canonical sequences using blood-derived patients' RNAs. In addition, the c.686-12A >G and c.1250-13G>A introduce de novo splice sites in introns 4 and 7, respectively. Splicing has been demonstrated to be affected by exonic variants, c.-21T>C (see above), by modifying the second nucleotide of exon 2, c.550G >A, c.550G >C and c.550G > T, by introducing substitutions on the last position of exon 3, c.685delG, with deletion of the last nucleotide of exon 4, and c.882C $>\mathrm{G}$ and c.884T $>\mathrm{G}$, with substitutions close to the 3' end of exon 5, as observed on patients'

This article is protected by copyright. All rights reserved. 
RNAs [Roche et al., 2005; Grodecká et al., 2017] and complemented by using a minigene construct [Grodecká et al., 2017].

Large deletions and duplications. These variants resulted from recombination promoted by two different Alu elements dispersed within SERPING1 gene [Carter et al., 1991]. Alu sequences are movable repetitive elements that are responsible for nearly $10 \%$ of the human genome and may represent hotspots for non-homologous recombination that could cause various hereditary diseases. Nineteen Alu sequences have been detected within the seven introns of SERPING1, most of them are found in introns 4 and 6 [Germenis \& Speletas, 2016]. These variants can be detected but not uncovered by MLPA, the reference technique for detection of large deletions and duplications/insertions [Kozlowski et al., 2008; Johnsrud et al., 2015]. Using MLPA could result in a false negative rate. Very recently, a precise mapping with identification of boundaries of multiexon deletion or duplication has been developed and standardized using a targeted next-generation sequencing platform [Loules et al., 2018], an Exon Quantitation Technique (EQT) [Nicolicht et al., 2019] or a combination of MLPA and direct sequencing of boundaries [Wong et al., 2019]. This accurate identification of 5' and 3' boundaries specifically establishes a deletion/duplication variant that differs or not from each other. Sixty-four variants of this category have been recorded in Supp. Table S4, but the boundaries have not been determined at the nucleotide level for most of them.

\subsection{Polymorphisms}

Many polymorphisms in SERPING1 gene that are not causative for HAE could have an impact on the phenotype, as observed in some examples (Supp. Table S6). SERPING1

This article is protected by copyright. All rights reserved. 
SNPs have been found to contribute to C1-INH-HAE with an incomplete penetrance and variations between alleles, eg. with deleterious consequence on SERPING1 gene expression; Supp. Table S6 shows some variants partially or not described in the databases gnomAD Browser ${ }^{\circledR}, 1000$ Genomes Browser ${ }^{\circledR}$ or Variation Viewer ${ }^{\circledR}$. (i) SNPs possibly affect splicing activities by introducing/disrupting intronic or exonic splicing regulatory elements [Wang \& Burge, 2008], eg. c.52-130C>T (rs1005510), c.129G > T;p.(Gly21=)/(Gly43=) $\quad$ (rs149573972), $\quad$ c.285C $>$ A;p. $($ Thr73=)/(Thr95=) (rs886048400), c.468C>T;p.(Ala134=)/Ala156=) ～(rs150601964), c.579G >A;p.Leu171=)/(Leu193=) (rs763981414), с.689T>C;p.Leu208Pro)/(Leu230Pro) (rs281875171), c.1218C>T;p.Ser384=)/(Ser406=) $\quad($ rs11229070) $\quad$ or $\quad$ c.1257C $>$ T (rs775042436). (ii) Exonic SNPs could be taken for pathogenic by the in silico applications SIFT $^{\circledR}$ and Poly-Phen2 ${ }^{\circledR}$, eg. c.461A>G;p.(Tyr132Cys)/(Tyr154Cys) (rs281875168), c.509C>T;p.(Ser148Phr)/(Ser170Phe) （rs281875169), c.550G>A;p.(Gly162Arg)/(Gly184Arg) ～(rs281875170), c.689T>C;p.(Leu208Pro)/(Leu230Pro) $\quad$ (rs281875171), c.695T>A;p.(Ile210Lys)/(Ile232Lys) ～(rs281875172), c.895T>C;p.(Trp277Arg)/(Trp299Arg) ～(rs281875173), c.1289T>A;p.(Leu408Gln)/(Leu430Gln) ～（rs281875174), c.1418T>G;p.(Val451Gly)/(Val473Gly) ～(rs281875177) or c.1475T>C;p.(Met470Thr)/(Met492Thr) (rs978962357). (iii) Pathogenic combinations of SNPs, eg. c.1030-20A>G (rs2511988) with c.922A>G;p.(Thr286Ala)/(Thr308Ala) (rs1802212) or with an exon 2 transition c.-21T>C (rs28362944), attributed to activate a cryptic acceptor site with exon 2 skipping, have been suggested to introduce a severe

This article is protected by copyright. All rights reserved. 
phenotype when present in trans with a deleterious variant [Cumming et al., 2003; Duponchel et al., 2006]. (iv) Other ones were informative, eg. c.1438G>A;p.(Val458Met)/(Val480Met) (rs4926) previously reported not to affect serpin function.

\subsection{Combined alleles}

It should be highlighted that compound heterozygosity of SERPING1 alleles with incomplete penetrance can cause pathogenicity as documented by the following $\begin{array}{llll}\text { examples. } & \text { (i) } \quad \text { combined } \quad \text { variant } \quad \text { c.[5C }>\mathrm{T}(;) 1045 \mathrm{C}>\mathrm{T}] \text {;[p.[(Ala- }\end{array}$ 21Val)/(Ala2Val)(;)p.(Leu327Phe)/(Leu349Phe)] was associated with a pathogenic HAEI phenotype by two daughters, while heterozygous parents are asymptomatic, with normal C1Inh function and expression. In a cis combination c.[49G>A(;)953C>G]; p.[(Gly6Arg)/(Gly17Arg)(;)p.(Ser296*)/(Ser318*)], the c.49G>A;p.(Gly-6Arg)/(Gly17Arg) allele exacerbated functional impairment of C1Inh caused by c.953C>G;p.(Ser296*)/(Ser318*), with a severe phenotype of the carrier [Xu \& Zhi, 2018]. With a trans combination of one recurrent and one novel C1Inh variant, c.[820A>G(;)856C>T]; p.[(Ile252Val)/(Ile274Val)(;)p.(Arg264Cys)/(Arg286Cys)] and c.[856C $>$ T(;)1361T >A ]; $\quad$ p.[(Arg264Cys)/(Arg286Cys)(;)p.(Val432Glu)/(Val454Glu)] were associated with HAE. (ii) Examples could be given by the above description of SNPs with c.-21T>C;rs28362944 conferring severity when combined in trans with another SERPING1 variant and c.1030-20A>G;rs2511988, also found associated with age-related macular degeneration [Kralovicova \& Vorechovsky, 2009], when combined with c.922A>G;p.(Thr286Ala)/(Thr308Ala);rs1802212; some other examples are found

This article is protected by copyright. All rights reserved. 
in Supp. Table S6. In addition to compound heterozygosity of different SERPING1 variants, a combination of a non-pathogenic SERPING1 variant and a variant in other HAE susceptibility genes can result in a severe C1-INH-HAE phenotype as shown by the following examples. (i) Combinations with other HAE susceptibility genes have been reported with a severe C1-INH-HAE phenotype, when SERPING1 variants are combined with c.-46C/T genotype of the F12 gene (rs1801020; MAF 0.472) [Bors et al., 2013; Speletas et al., 2015b] and c.51+3A $>\mathrm{G}$ variant of the SERPING1 gene with c.1032C>A;p.(Thr309Lys)/(Thr328Lys) of the F12 gene [Charignon et al., 2018]. (ii) In almost all symptomatic patients of a big pedigree presenting with C1Inh deficiency, multiple allele combinations have been identified with c.1369G>C;p.(Ala435Pro)/(Ala457Pro) variant of the SERPING1 gene and ACE [c.970C>T;p.(Arg324Trp)], $\quad$ ENPEP [c.638A>G;p.(Gln213Arg)], $\quad K L K 1$ [c.433G>C;p.(Glu145Gln) or $\quad$ c.556A>G;p.(Lys186Glu)], $\quad$ KLKB1 (c.428G>A;p.(Ser143Asn) or $\quad$ c.1679G>A;p.(Arg560Gln)], KNG1 (c.533T>C;p.(Met178Thr) or $\quad$ c.591T>G;p.(Ile197Met)], $\quad$ NOS3 (c.894T>G;p.(Glu298Asp) or c.2654G>T;p.(Arg885Met)] and PRCP (c.336A>T;p.(Glu112Asp)] alleles [Veronez et al., 2016]. These observations are congruent with the emerging concept where symptomatic manifestations of C1Inh deficiency should be, at least partially, determined by genetic variations in another/other gene(s) encoding protein(s) involved in kinin metabolism pathways.

This article is protected by copyright. All rights reserved. 


\subsection{De novo variants}

Probands presenting with SERPING1 de novo variants were identified ( $\mathrm{n}=73)$, that might represent $5.6 \%$ of the probands (73/1294), a number that possibly may be related to the kindreds, but lower than that has been reported [Pappalardo et al., 2000; Germenis and Speletas, 2016]. These sporadic cases of angioedema were clinically and biochemically indistinguishable from those with a proven family story. Corresponding variants (missense/nonsense, short deletion/duplication/insertion, splicing defect, large deletion) were distributed between all the exons and exon/intron boundaries.

\subsection{Unsuccessful findings in probands with C1-INH-HAE}

Taken from our probands and using Sanger and MLPA methods, no SERPING1 gene alterations have been identified in 24 pedigrees presenting with biological and clinical criteria of C1-INH-HAE (24/379; 6.3\%). This percentage value is in agreement with other studies. As suggested by Speletas et al. [2014], a causative defect modifying C1Inh expression may be located in an intronic or untranslated region of the gene, and posttranslational alterations affecting protein structure and/or function could explain unsuccessful molecular analyses in a few probands. As recently demonstrated by Nicolicht et al. [2019], EQT could be advantageously developed for detection of large rearrangements of SERPING1, with reports of their boundaries in C1INH-HAE patients, whereas no variants in SERPING1 has been identified by conventional methods. Beside, analysis of transcripts could support the identification of variants in unsuccessful findings.

This article is protected by copyright. All rights reserved. 


\section{FUNCTIONAL PHENOTYPE}

\subsection{Haploinsufficiency of C1-INH-HAE}

Most HAE-I patients are heterozygous for variants in the SERPING1 gene and maintain production of functional C1Inh only from a single wild-type SERPING1 allele. Surprisingly and rather than the $50 \%$ value that might be expected, plasma values of C1Inh are usually 5-30\% of normal. This reduction could be caused by degradation/inactivation of the variant carrying allele by means that prevent (co-) transcription or abolish mRNA expression post transcriptionally. Laimer et al. [2006] proposed that C1Inh deficiency leads to a similar/analog dosage-dependent loss of C1Inh function induced by haploinsufficiency. A subsequent increased activation of some or all of the zymogens under C1Inh control and the subsequent higher catabolism of remaining C1Inh, a decreased production or compromised intracellular transport and segregation of the protein have been suggested to account for this phenomenon [Woo et al., 1985]. Regarding the genetic aspect with a transmission according to a dominant mode, some cases with biallelic SERPING1 variants are contradictory. Pertaining to this hypothesis, most of homozygous probands carry non-recurrent variants, where heterozygosity has exceptionally been found associated with a clinical phenotype. Taking the c.1385T>G;p.(Ile440Ser)/(Ile462Ser) variant as an illustrative example, the clinical manifestations segregated in the pedigree according to an autosomal recessive mode of inheritance; both homozygotes were affected (Supp Table S7). Even if antigenic C1Inh

and function were found lower than normal in the heterozygous individuals, only one in five carriers was pauci-symptomatic [Blanch et al, 2006]. The homozygous patients

This article is protected by copyright. All rights reserved. 
exhibited low antigenic C1Inh and function because of its cleavage, consumption, or both, in concordance with their higher complement or KKS activation, but not attributed to a loss of c.1385T $>\mathrm{G}$ allele expression. Heterozygotes also presented with a cleaved C1Inh and a remaining C1Inh function measured in plasma attributed to the wild type allele: The c.1385T>G;p.(Ile440Ser)/(Ile462Ser) caused a lack of function but did not severely affect the secretion/function of the wild type allele, consistently with a slight C4 level reduction. Importantly, Haslund et al [2019] demonstrated that C1Inh variants encoded by a subset of C1-INH-HAE-causing SERPING1 alleles affected secretion of wild-type C1Inh protein in a dominant negative fashion by triggering formation of protein-protein interactions between normal and mutant C1Inh. These alleles include c.508T $>$ C,$\quad$ p.(Ser170Pro)/(Ser148Pro); $\quad$ c.530T $>$ C,$\quad$ p.(Leu177Pro)/(Leu155Pro); c.566C >A， p.(Thr189Asn)/(Thr167Asn); $\quad$ c.707T>C， p.(Phe236Ser)/(Phe214Ser); c.773A>T, p.(Asn258Ile)/(Asn236Ile); c.871A>C, $\quad$ p.(Asn291His)/(Asn269His); c.1322T>C， p.(Met441Thr)/(Met419Thr); c.1342G>C， p.(Glu448Gln)/(Glu426Gln); c.1417G >A， p.(Val473Met)/(Val451Met); c.1427C >T, p.(Pro476Leu)/(Pro454Leu) (Supp. Table S1). Subsequent intracellular C1Inh aggregates were trapped in the endoplasmic reticulum, disrupting the expression of the wild-type protein.

\subsection{Identification of an intermediate C1-INH-HAE type}

The abundance of missense variants prompted a study aimed at investigating the possible expression of C1Inh alleles. In order to test this hypothesis, we took as a basis the early observation of a distinction between HAE-I and HAE-II developed by Rosen et al. [1965], where HAE-II diagnostic is retained when an abnormal, non-functional protein is

This article is protected by copyright. All rights reserved. 
synthesized. Thus, C1-INH-HAE patient samples were investigated using anti-C1Inh immunoblot analysis. After incubation of a patient sample with target protease, a nonfunctional C1Inh variant product was identified by its $\mathrm{Mr}$ and ascribed to a biological deficient phenotype with failed serpin-protease association and a residual 105-kDa molecular species on SDS-PAGE (Figure 3). Seventy-three C1-INH-HAE probands presenting with low antigenic C1Inh and non-functional C1Inh variants have been identified, with 40 variants including 14 new ones (Supp. Tables S1 and -2). This type mimics HAE-I through low C1Inh levels, on the one hand, and HAE-II through expression of SERPING1 variant, on the other hand. The corresponding C1Inh-deficient condition could be referred to as intermediate type, ie. HAE-intermediate, in agreement with Bors et al. [2013], and indicated as INT in Supp. Tables S1 and -S2. The variants associated with HAE-intermediate biological phenotype are distributed within exons 3-8 (Figure 4) and covers the entire serpin domain, with hot spots in identified structural domains, ie. mainly shutter, gate and breach (Figure 1B, -C).

Pertaining to the model developed by Haslund et al [2019], the HAE-intermediate type identifies some C1Inh deficiency situations where the intracellular non-functional allele is expressed, but circulating at low rate and mimicking a HAE-I phenotype. These variants with multimerisation ability are introduced in Class III of missense variants, as developed below and shown in Table 1. The effect of frameshifts, large deletions and duplications could be readily explained as being associated with HAE-I condition.

This article is protected by copyright. All rights reserved. 


\section{GENOTYPE-FUNCTIONAL PHENOTYPE}

The trypsin-like Serine protease specificity of serpins is primarily determined by the nature of the residue at the $\mathrm{P} 1$ and $\mathrm{P} 2$ positions, ie. $\mathrm{Arg}^{444}$ and $\mathrm{Ala}^{443}$ for C1Inh. The control capacity of C1Inh is attributable to its ability to target a protease and to trap it according to the mousetrap model of serpins. As proposed by Bos et al. [2002], C1Inh requires adequate exposure of the RCL (Figure 1B), with the association constant $\left(\mathrm{k}_{\text {on }}\right)$ reflecting the rate of protease binding. The protease requires a fast insertion of the RCL into the central $\beta$-sheet after bonding between the active site Serine of the protease and the P1 $\operatorname{Arg}^{444}$ of C1Inh. The ability to keep the protease trapped is expressed with the dissociation constant $\left(\mathrm{k}_{\mathrm{off}}\right)$. Bos et al. [2002] suggested that a molecule with a high $\mathrm{k}_{\mathrm{on}}$ and a high $\mathrm{k}_{\text {off }}$ is not an inhibitor, but rather a suitable substrate. Subsequently, the SERPING1 variants associated with HAE-II (and HAE-intermediate, as well) were categorized into three classes: (i) Class I included variants that lead to altered exposure of the active site, eg. variants at the P1 $\mathrm{Arg}^{444}$ and P2 $\mathrm{Ala}^{443}$, influencing target protease recognition;; (ii) Class II comprised variants leading to disturbed insertion of the RCL into central $\beta$-sheet, the serpin then becoming a substrate instead of an inhibitor with insufficient trapping mechanism, eg. proximal loop-reactive hinge mutants at the P14, P12, and P8 residues of C1Inh, ie. $\mathrm{Val}^{432}, \mathrm{Ala}^{434}$, or Ser ${ }^{438}$ [Davis, 1997], and of the other serpins [Stein \& Carrell, 1995; Irving et al., 2000], as well; (iii) Class III represented variants with spontaneous insertion of the RCL into the $\beta$-sheet A of the same or another molecule, producing a latent structure or polymers; eg. variants observed in the Cterminal hinge region [Eldering et al., 1995], or afflicting C1Inh at the shutter or the breach region [Madsen et al., 2014, Haslund et al. 2019]. As now being set for plasma

This article is protected by copyright. All rights reserved. 
[Madsen et al., 2014] and within cell [Haslund et al., 2019], methods to identify C1Inh oligomers will introduce variants into Class III. Oligomerised C1Inh has been demonstrated to promote kallikrein-system activation [Madsen et al. 2015], subsequently accounting for an amplification process of kinin forming in C1-INH-HAE pathophysiology. Table 1 shows the phenotypic distribution of some SERPING1 variants, mostly of the HAE-II and HAE-intermediate groups. By using the rating system in 3 classes, introduction of variants in 2 or 3 classes, eg. at positions $\mathrm{Asn}^{250}, \mathrm{Arg}^{378}, \mathrm{Val}^{432}$, $\mathrm{Ala}^{434}, \mathrm{Ala}^{436}, \mathrm{Ser}^{438}$ (Table 1), suggests that there is no single mechanism underlying molecular dysfunction.

HAE-II phenotype is commonly attributed to a qualitative defect, and characterised by normal (or elevated) plasma C1Inh concentrations associated with low C1Inh function, and it traditionally accounts for 15\% of all C1Inh-deficient cases. This condition has been shown to be associated with missense variants located mainly at exon 8 within the RCL (Figure 4A), as well as at two critical hinge regions upstream (proximal hinge) and downstream (distal hinge) of the RCL, but not in the shutter or the gate (Figures 1C, -D). Other ones have been observed in conditions of in-frame deletion/duplication variants at positions $\mathrm{Ile}^{174}-\mathrm{Tyr}^{177}, \mathrm{Ile}^{174}-\mathrm{His}^{185}, \mathrm{Asn}^{250}, \mathrm{Lys}^{251}, \mathrm{Ser}^{258}-\mathrm{Pro}^{260}, \mathrm{Val}^{266}, \mathrm{Val}^{300}, \mathrm{Met}^{303}$ and Gly ${ }^{431}$ (Supp. Table S2). Missense variants associated with an intermediate type distributed throughout exons 3 to 8 (Figure 4B).

This article is protected by copyright. All rights reserved. 


\section{STRUCTURE-FUNCTIONAL PHENOTYPE}

\subsection{Structure-functional phenotype associations}

Native and latent C1Inh structures show how missense variants cluster in the 3-D space (Figures 1B, -C; respectively). Some variants are illustrated on the structure, in line with their distribution into three functional classes, as developed above (Table 1). Those that alter crucial positions maintaining correct protease specificity, ie. variants of Class I, were predominantly found around the RCL. This observation is pertaining to the substitutions of the P1 $\mathrm{Arg}^{444}$, and the adaptation of secondary C1s interaction site residues $\mathrm{Gln}^{453}$ and Phe $^{455}$ (identified by He et al. [1997]), with the p.(Phe455Ser)/(Phe477Ser) variant. More intriguingly, the p.(Leu129Arg)/(Leu151Arg) variant, in a conserved position among serpins, exhibits a loss of C1s protease control, but an unaffected control of contact phase [Ghannam et al., 2015]. Beside, p.(Arg378Cys)/(Arg400Cys) displays a strongly decreased capacity to associate with kallikrein and retains a partial control of C1s protease [López-Lera et al., 2010; Ghannam et al., 2015]. Similarly the P2 p.(Ala443Val)/(Ala465Val) variant had diminished activity against C1r and C1s but normal activity against plasma kallikrein and factor XIIa [Zahedi et al., 1995; Zahedi et al., 1997]. Residues that prevent conversion to a substrate and disrupt serpin inhibitory capacity, ie. those of Class II, are located in the $\beta$-sheet $\mathrm{C}$ and the hinge region (Table 1 ). The corresponding C1Inh variants could be associated with the failed mousetrap functionality, either by inefficient or preliminary trapping. Examples are given with positions $\operatorname{Pro}^{377}, \mathrm{Arg}^{378}$ and $\mathrm{Met}^{387}$, located in the central $\beta$-sheet (or nearby, at start of helix I), with the molecular species p.(Pro377Ser)/(Pro399Ser), 
p.(Arg378Cys)/(Arg400Cys) and p.(Met387Thr)/(Met409Thr) serving as a substrate, due to inefficient protease trapping, and subsequent serpin cleavage. Hydrophobic residues in the $\beta$-sheet $\mathrm{C}\left(\mathrm{Phe}^{291}, \mathrm{Val}^{300}, \mathrm{Gly}^{323}\right)$ and a surface coil $\left(\mathrm{Phe}^{281}\right)$, corresponding to gate residues, have variants with inefficient trapping, suggesting their attribution into Class II. C1Inh RCL residues aligned with A1AT, P14, P12, P10 and P8 positions have short sidechains and are thought to permit efficient and rapid insertion of the RCL into the $\beta$-sheet A. Variants of hinge-region residues often convert inhibitory serpins into substrates (Table 1). The variant p.(Ala434Glu)/(Ala456Glu) is a good illustration, with (i) $\mathrm{Ala}^{434}$ substituted by a long side-chain residue and (ii) $\mathrm{Ala}^{434}$ aligning with the P12 residue of the serpins (Table 2). Besides, p.(Ala434Glu)/(Ala456Glu) was demonstrated to be susceptible to cleavage by C1s and contact phase proteases, but did not form complexes with them [Skriver et al., 1991]. Finally, variants anchoring the RCL and located in the distal hinge are critical for loop overinsertion or multimerisation and are introduced into Class III (Table 1), eg. p.(Pro454Leu)/(Pro476Leu) and p.(Pro476Thr)/(Pro498Thr) variants in conserved positions (Table 2). Interestingly, the observation of qualitative C1Inh defects opens the field for further investigations with unique opportunities to pinpoint the role of strategic residues in distinct protease control, latent structure or oligomerisation. The situation of $\mathrm{Asn}^{250}$ is specific, because it is located in a loop protruding and overlying the central $\beta$-sheet. Deletion and duplication of this residue are likely to alter the structure of this strategic central $\beta$-sheet (Figure 1D; Table 2), with possible subsequent oligomerisation, as observed for the Lys ${ }^{251}$ deletion mutant [Zahedi et al., 1996](Figure 1E), but not conversion into a substrate (Table 1). Ala ${ }^{436}$ is a RCL residue (aligned to P10 in A1AT) whose side chain becomes buried upon RCL

This article is protected by copyright. All rights reserved. 
incorporation (Figure 1E). P.(Ala436Thr)/(Ala458Thr) and p.(Ala436Val)/(Ala458Val) variants, unlike similar variants of other serpins, are not cleavable by target proteases. By increasing the interaction with $\mathrm{Lys}^{307}$ or $\mathrm{Lys}^{306}$, the RCL of p.(Ala436Thr)/(Ala458Thr) and p.(Ala436Val)/(Ala458Val) packed even better in the loop-inserted latent structure than in that of the wild-type residue [Beinrohr et al., 2007](Figures 1C, -E). Both variants favour overinsertion up to P10 with release of s1C from the $\beta$-sheet C likely to prevent RCL cleavage [Aulak et al., 1993a; Stein \& Carrell, 1995]. Other examples of Class III variants could be p.(Pro454Leu)/(Pro476Leu), in the gate region, or p.(Thr167Asn)/(Thr189Asn), a variant in a position out of the functional regions of the serpins, and which was clearly shown to develop oligomers [Madsen et al., 2014]. The p.(Pro476Thr)/(Pro498Thr), analog of p.(Pro476Ser)/(Pro498Ser) described by Eldering et al. [1995] and Bors et al. [2013], that facilitates the interaction of Pro ${ }^{391}$ with P8'-P11'P12' residues, could promote a presumably latent variant and polymer formation [Beinrohr et al., 2007]. Surprisingly, the variant p.(Cys108Tyr)/(Cys130Tyr) in the Nterminus presumably lowers molecular stability and induces a latent conformation by removing a cysteine involved in an intramolecular disulphide bridge. Consistent observations of variants promoting oligomerisation/multimerisation would emphasise that C1-INH-HAE could undergo a serpinopathy archetypal process, similar to that causing most of serpin-related diseases. Furthermore, the great majority of the missense variants located in or in contact with the central $\beta$-sheet or afflicting the shutter region were found to be associated mainly with HAE-I. These are likely to promote oligomerisation, to compromise RCL functionality, or to cause protein instability or misfolding, and also to retain mutants within producing cells. The latter was demonstrated by Haslund et al

This article is protected by copyright. All rights reserved. 
[2019] for some positions involved in the shutter region: $\mathrm{Ser}^{148}$, $\mathrm{Leu}^{155}, \mathrm{Phe}^{214}, \mathrm{Val}^{266}$ and $\operatorname{Asn}^{269}$ (Figure 1B, -C; Table 1).

\subsection{Lesson from variants at conserved positions in the serpin family}

Certain mutated positions showed high residue conservation among serpins (Table 2); among 35 positions mapped onto the model of C1Inh structure, and referred to as a mousetrap function of C1Inh: RCL, gate, shutter, and breach (Table 2), 17 corresponded to buried positions, ie. accessible surface area $\leq 20 \AA^{2}$, and 2 to exposed residues, eg. $\mathrm{Asn}^{250}$ and $\mathrm{Arg}^{378}$ (Figures 1D, -E). Residue substitutions at conserved positions have important consequences. Table 2 shows some examples: (i) destabilization of the central

$\quad \beta$-sheet, $\quad$ eg. $\quad$ p.(Phe147Ser)/(Phe169Ser), $\quad$ p.(Pro149Gln)/(Pro171Gln), p.(Val468Asp)/(Val490Asp) in the shutter, (ii) exposed positions of residues involved in strategic functions, eg. p.(Arg378Cys)/(Arg400Cys) with polyanions, (iii) disruption of RCL insertion into the central $\beta$-sheet, eg. p.(Ala434Glu)/(Ala456Glu). Interestingly, apparent correspondences of SERPING1 variants have been found with those of the prototypical serpin A1AT, eg. p.(Ser148Pro)/(Ser170Pro), p.(Gly162Arg)/(Gly184Arg), p.(Met302Arg)/(Met324Arg), p.(Arg378Cys)/(Arg400Cys), p.(Glu429Lys)/(Glu451Lys) (with the Z allele of AIAT), p.(Pro454Leu)/(Pro476Leu) and variants at position Pro ${ }^{476}$.

A fine and precise molecular and structural understanding of the consequences of each variation is far beyond the scope of this update, because of the underlying complexity of the dynamical conformational changes and plasticity, which are key to both the function and dysfunction of serpins. In addition to the well-described key regions such as gate, breach and shutter, a cluster of variant positions can be observed at the 'bottom' of the

This article is protected by copyright. All rights reserved. 
molecule, eg. including $\mathrm{Thr}^{167}$ (Figure 1B, -C). An initial key to start to understand the possible influence of variants in this area is the fact that aggregation-prone intermediates are believed to form either during the folding process or by dynamic sampling of sheetopen states. This 'bottom' part of the molecule has been recently shown in the case of A1AT to display a lag phase in its folding kinetics [Tsutsui et al., 2012]. Furthermore, it also corresponds to more labile segments observed during local unfolding leading to transient sheet-open states, where destabilizing variants are more frequently observed [Krishnan \& Gierasch, 2011].

\section{Serping1-DEFICIENT MOUSE MODELS}

To investigate the role of C1Inh in vivo, and to determine how bradykinin is involved in the induction of vascular permeability, C1Inh-deficient mice have been produced. Serping1 gene was targeted 210 bp upstream of exon 7 [Han et al., 2002], or was inactivated by disrupting the donor splice site of intron 2 [Oschatz et al., 2009]. Serping1/- animals have increased vascular permeability, as demonstrated by the extravasation of Evans Blue dye. Another mouse model that mimics human HAE only at the metabolic level, with decreased plasma C1Inh and C4 levels, has been created using CRISPR/Cas9 technology with the introduction of a 10-nt deletion in exon 3 (c.159_168del; NCBI \#NM_009776.3) [Qiu et al., 2019]. These mouse models do not reproduce the HAE phenotype, thus limiting its interest. Interestingly Farfara et al. [2019] knocked down circulating C1Inh in wild-type mice in order to understand the effect of plasma C1Inh on brain pathology via the vascular system, with observations pertaining to former clinical

This article is protected by copyright. All rights reserved. 
observations with C1Inh deficiency described as angioneurotic oedema and the role of C1Inh as a gatekeeper to the brain via the neurovascular system.

\section{CONCLUSIONS}

Biological diagnostic. In line with the original description of HAE-II [Rosen et al., 1965], we suggest that HAE-II should be identified using a biological phenotype criterion detecting the production of a dysfunctional C1Inh protein that resulted in low C1Inh function, regardless of whether antigenic C1Inh levels were normal or reduced. In our study, patients displaying low antigenic and functional C1Inh associated with the variant expression were classified as HAE-intermediate. Anti-C1Inh immunoblot analysis should be recommended for qualifying any C1-INH-HAE associated with a missense variant, with an identification of any qualitative defect in allele product expression. Subsequently, HAE-II and -intermediate conditions were found in 30\% of C1-INH-HAE patients of our series.

Genetic investigations. Several reasons for SERPING1 allelic heterogeneity have been developed by Germenis and Speletas [2016]. A deeper knowledge of transcriptome signatures [López-Lera et al., 2013] is expected to be gained in the coming years, with a contribution of epigenetic elements, gene-gene or gene-environment that regulate gene expression and biological processes, as recently suggested by Maia et al. [2019]. This important issue will lead to a better understanding of C1-INH-HAE pathophysiology and interpretation of genetics of C1-INH-HAE. As suggested by Grodecká et al. [2017], interpretation of genotypes with variants in the introns and at the exon/intron boundaries should be recommended with demonstration of exon skipping.

This article is protected by copyright. All rights reserved. 
Prospects in genetics and biology. The arrival of next-generation sequencing methods has dramatically improved the diagnosis of human genetic diseases. On the one hand and because of the massively parallel sequencing approach allowing more deep sequencing, the new technologies of second-generation sequencing are more sensitive to detect postzygotic variants [Xu et al., 2015], a condition where patients were sporadic cases, with two affected siblings or more and unaffected relatives in the same or previous generation. A good example is given by Ebo et al [2018] with genetic investigations of SERPING1 and SNPs on peripheral and gonadal parent samples, in addition to the samples of index case and her sister. On the other hand, when applied to multiple alleles, next-generation sequencing can ascertain the abundance of allele combinations [Veronez et al., 2016; Loules et al., 2018]. Its precise incidence would be more systematically addressed by investigating the group of de novo variants. On the basis of data pertaining to structural biology and serpin function, identification of dysfunctional variants that shows a partial expression defect, eg. for HAE-intermediate patients, underlines the importance of accurate genotyping of patients with angioedema manifestations. Genotypes with missense variants must be interpreted in a close relationship with biological investigation fitting with C1Inh typing, including in HAE-intermediate situations. Any SERPING1 variant reminiscent of dysfunctional phenotype of serpin with multimerisation or latency should be identified as serpinopathy.

\section{Acknowledgments}

Prof Joel Lunardi, Drs Julien Fauré and Gaelle Hardy, Laboratoire Biochimie et Génétique Moléculaire, CHU Grenoble Alpes, Grenoble, France, have contributed

This article is protected by copyright. All rights reserved. 
importantly to identify the variants of the pedigrees recorded in the registry of the French Reference Center for Angioedema CREAK and we thank them warmly. We are grateful to the physicians of the CREAK network, the French National Centre for Angioedema, and to other people for having participated in the collaborative study and fruitful discussions: K Djenouhat, Algiers; L Martin, Angers; M Vigan and F Pelletier, Besançon; S Guez, Bordeaux; Y Ollivier, Caen; L Faivre, Dijon; D-A Moneret-Vautrin and E Beaudouin, Epinal; L Arlettaz, P Taramarcaz and M Gil, Geneva; C Jacquot, L Bouillet, I Boccon-Gibod, A Pagnier, Grenoble; A Leimgruber, Lausanne; J Gooi, Leeds; L de Lumley, Limoges; B Coppéré, Lyon; H Maillard, Le Mans; D Launay and I Pruvost, Lille; J-R Harlé, J-J Grob and S Gayet, Marseille; B Graffin, Metz; N Raison-Peyron, Montpellier; M Morisset and G Kanny, Nancy; PY Jeandel, Nice; D Vincent, Nîmes; C Delaunay, Niort; P Hutin, Quimper; O Fain and A Gompel, Paris; P Roblot, Poitiers; S Geny, Strasbourg; J Moreau, Toulouse. The authors are indebted to Dr B Favier and F Parsopoulou, Grenoble, and Dr L Truedsson, Lund, for helpful comments, to F Csopaki, V Reininger, P Sellier and M Allegret-Cadet, Grenoble, and to H Humeau, Angers, for their skilful assistance. We are also grateful to the physicians from Hospital La Paz and to those collaborating with Unidad de Inmunología from Hospital La Paz for providing the clinical samples included in this work: Dr. T Caballero, Madrid; Dr. C Marcos, Vigo; Dr. M Pedrosa, Madrid; Dr. R Cabañas, Madrid; Dr. MA Rico, A Coruña; Dr. M Guilarte, Barcelona; Dr. A Giacobino, Geneva; Dr. M. Corominas, Barcelona; Dr. V Rodrigo, A Coruña; Dr. J Figueroa, Las Palmas; Dr. C Colas, Zaragoza; Dr. M López, Madrid and Dr. D Rivero, Madrid.

This article is protected by copyright. All rights reserved. 


\section{Author contributions}

CD coordinated the research program, with its conceptualization, funding acquisition, and supervision; CD and DP were responsible for the methodology, planning and performance of experiments, data analysis, and manuscript writing - review \& editing; IWB, ALL, DR, MT and MLT developed the molecular genetics and subsequent data curation; CG introduced residue positions in the 3D-model and developed their interpretation; DC, AG, ALL, DP and MLT developed the biochemical experimental work; DC and DP conducted the statistical analyses; all authors have read and approved the final manuscript.

\section{Funding}

This work was supported by programs conducted within the French Programme Hospitalier de Recherche Clinique (promoter: CHU Grenoble; PHRC 1996, coordinator: Claude Jacquot; PHRC 2002, coordinator: Claude Jacquot \#DGS:2002/0649), the European Framework Program 5 (acronym PreHAEAT; coordinator: Marco Cicardi), the KininX funding, the National Rare Disease Program from the French Ministry of Health (promoter: CHU Grenoble Alpes; National Reference Center for Angioedema CREAK) and Ministerio de Economía y Competitividad (AES2015: PI15/00255).

This article is protected by copyright. All rights reserved. 


\section{References}

Aabom, A., Andersen, K. E., Fagerberg, C., Fisker, N., Jakobsen, M. A., \& Bygum, A. (2017). Clinical characteristics and real-life diagnostic approaches in all Danish children with hereditary angioedema. Orphanet Journal of Rare Diseases, 12(1),55. doi: 10.1186/s13023-017-0604-6.

Adzhubei, I., Jordan, D. M., \& Sunyaev, S. R. (2013). Predicting functional effect of human missense mutations using PolyPhen-2. Current Protocols in Human Genetics Chapter 7: Unit7.20.

Agostoni, A., Aygören-Pürsün, E., Binkley, K. E., Blanch, A., Bork, K., Bouillet „L, ... Zingale, L. (2004). Hereditary and acquired angioedema: problems and progress: proceedings of the third C1 esterase inhibitor deficiency workshop and beyond. The Journal of Allergy and Clinical Immunology, 114(3 Suppl),S51-S131. doi:10.1016/j.jaci.2004.06.047.

Andrejević, S., Korošec, P., Šilar, M., Košnik, M., Mijanović, R., Bonači-Nikolić, B., \& Rijavec, M. (2015). Hereditary Angioedema due to C1 Inhibitor deficiency in Serbia: Two novel mutations and evidence of genotype-phenotype association. PLoS One, 10(11),e0142174. doi:10.1371/journal.pone.0142174.

Aradhya, S., Lewis, R., Bonaga, T., Nwokekeh, N., Stafford, A., Boggs, B., ... Suchy S. (2012). Exon-level array CGH in a large clinical cohort demonstrates increased sensitivity of diagnostic testing for Mendelian disorders. Genetics in Medicine, 14(6),594-603. doi:10.1038/gim.2011.65.

This article is protected by copyright. All rights reserved. 
Ariga, T., Igarashi, T., Ramesh, N., Parad, R., Cicardi, M., \& Davis 3 ${ }^{\text {rd }}$ A. E. (1989). Type I C1 inhibitor deficiency with a small messenger RNA resulting from deletion of one exon. The Journal of Clinical Investigation, 83(6),1888-1893.

Aulak, K. S., Cicardi, M., \& Harrison, R.A. (1990). Identification of a new P1 residue mutation $(444 \mathrm{Arg} \rightarrow \mathrm{Ser}$ ) in a dysfunctional $\mathrm{C} 1$ inhibitor protein contained in a type II hereditary angioedema plasma. FEBS Letters, 266(1-2),13-16.

Aulak, K. S., Davis 3 ${ }^{\text {rd }}$, A. E., Donaldson, V. H., \& Harrison, R. A. (1993a). Chymotrypsin inhibitory activity of normal C1-inhibitor and a P1 Arg to His mutant: evidence for the presence of overlapping reactive centers. Protein Science, 2(5),727-732.

Aulak, K. S., Eldering, E., Hack, C. E., Lubbers, Y. P., Harrison, R. A., Mast, A., ... Davis $3^{\text {rd }}$, A. E. (1993b). A hinge region mutation in C1-inhibitor (Ala436 $\rightarrow$ Thr) results in nonsubstrate-like behavior and in polymerization of the molecule. The Journal of Biological Chemistry, 268(24),18088-18094.

Bafunno, V., Divella, C., Sessa, F., Tiscia, G. L., Castellano, G., Gesualdo, L., ... Montinaro, M, (2013). De novo homozygous mutation of the C1 inhibitor gene in a patient with hereditary angioedema. The Journal of Allergy and Clinical Immunology, 132(3),748-750.e3. doi:10.1016/j.jaci.2013.04.006.

Bafunno, V., Bova, M., Loffredo, S., Divella, C., Petraroli, A., Marone, G., ... Triggiani, M. (2014). Mutational spectrum of the C1 inhibitor gene in a cohort of Italian patients with hereditary angioedema: description of nine novel mutations. Annals of Human Genetics, 78(2),73-82. doi:10.1111/ahg.12052.

This article is protected by copyright. All rights reserved. 
Beinrohr, L., Harmat, V., Dobó, J., Lörincz, Z., Gál, P., \& Závodszky P. (2007). C1 inhibitor serpin domain structure reveals the likely mechanism of heparin potentiation and conformational disease. The Journal of Biological Chemistry, 282(29),21100-21109. doi:10.1074/jbc.M700841200.

Bissler, J. J., Cicardi, M., Donaldson, V. H., Gatenby, P. A., Rosen, F. S., Sheffer, A. L., \& Davis $3^{\text {rd }}$, A. E. (1994a). A cluster of mutations within a short triplet repeat in the C1 inhibitor gene. Proceedings of the National Academy of Sciences of the United States of America, 91(20),9622-9625.

Bissler, J. J., Donaldson, V. H., \& Davis III, A. E. (1994b). Contiguous deletion and duplication mutations resulting in type 1 hereditary angioneurotic edema. Human Genetics, 93(3),265-269.

Bissler, J. J., Aulak, K. S., Donaldson, V. H., Rosen, F. S., Cicardi, M., Harrison R. A, \& Davis 3rd A. E. (1997). Molecular defects in hereditary angioneurotic edema. Proceedings of the Association of American Physicians, 109(2),164-173.

Blanch, A., Roche, O., López-Granados, E., Fontán G., \& López-Trascasa, M. (2002). Detection of $\mathrm{C} 1$ inhibitor (SERPING1/C1NH) mutations in exon 8 in patients with hereditary angioedema: evidence for 10 novel mutations. Human Mutation, 20(5),405406.

Blanch, A., Roche, O., Urrutia, I., Gamboa, P., Fontan, G., \& López-Trascasa, M. (2006). First case of homozygous C1 Inhibitor deficiency. The Journal of Allergy and Clinical Immunology,118(6),1330-1335. doi:10.1002/humu.9073.

This article is protected by copyright. All rights reserved. 
Bors, A., Csuka, D., Varga, L., Farkas, H., Tordai, A., Füst, G., \& Szilagyi, A. (2013). Less severe clinical manifestations in patients with hereditary angioedema with missense C1INH gene mutations. The Journal of Allergy and Clinical Immunology, 131(6),17081713. Doi:10.1016/j.jaci.2012.11.015.

Bos, I. G., Hack, C. E., \& Abrahams, J. P. (2002). Structural and functional aspects of C1-inhibitor. Immunobiology, 205(4-5),518-533. Doi:10.1078/0171-2985-00151

Bos, I. G., Lubbers, Y. T., Roem, D., Abrahams, J. P., Hack, C. E., \& Eldering, E. (2003). The functional integrity of the serpin domain of C1-inhibitor depends on the unique $\mathrm{N}$ terminal domain, as revealed by a pathological mutant. The Journal of Biological Chemistry, 278(32),29463-29470. doi:10.1074/jbc.M302977200.

Bowen, B., Hawk, J. J., Sibunka, S., Hovick, S., \& Weiler, J. M. (2001). A review of the reported defects in the human C1 esterase inhibitor gene producing hereditary angioedema including four new mutations. Clinical Immunology, 98(2),157-163. doi:10.1006/clim.2000.4947.

Büyüköztürk, S., Eroğlu, B.K., Gelincik, A., Uzümcü, A., Ozşeker, F., Colakoğlu, B., ... Uyguner, Z. O. (2009). A Turkish family with a novel mutation in the promoter region of the C1 inhibitor gene. The Journal of Allergy and Clinical Immunology, 123(4),962-964. doi:10.1016/j.jaci.2008.12.022.

Bygum, A., Fagerberg, C.R., Ponard, D., Monnier, N., Lunardi, J., \& Drouet, C. (2011). Mutational spectrum and phenotypes in Danish families with hereditary angioedema 
because of C1 inhibitor deficiency. Allergy, 66(1),76-84. doi:10.1111/j.13989995.2010 .02456 .

Cagini, N., Veronez, C. L., Constantino-Silva, R. N., Buzolin, M., Martin, R. P., Grumach, A. S., \& Pesquero, J. B. (2016). New mutations in SERPING1 gene of Brazilian patients with hereditary angioedema. Biological Chemistry, 397(4),337-344. doi:10.1515/hsz-2015-0222.

Carter, P. E., Duponchel, C., Tosi, M., \& Fothergill, J. E. (1991). Complete nucleotide sequence of the gene for human C1 inhibitor with an unusually high density of Alu elements. European Journal of Biochemistry, 197(2),301-308.

Charignon, D., Ghannam, A., Ponard, D., \& Drouet, C. (2017). Hereditary C1 inhibitor deficiency is associated with high spontaneous amidase activity. Molecular Immunology, 85,120-122. doi:10.1016/j.molimm.2017.01.028.

Charignon, D., Ponard, D., de Gennes, C., Drouet, C., \& Ghannam, A. (2018). SERPING1 and F12 combined variants in a hereditary angioedema family. Annals of Allergy, Asthma and Immunology, 121(4),500-503. doi:10.1016/j.anai.2018.05.031.

Chen, Y. J., Shyur, S. D., Lei, W. T., \& Kao, Y. H. (2016). Type II hereditary angioedema: The first case report in Taiwan. Journal of the Formosan Medical Association, 115(8),680-681. doi.org/10.1016/j.jfma.2015.12.006.

Colobran, R., Lois, S., de la Cruz, X., Pujol-Borrell, R., Hernández-González, M., \& Guilarte, M. (2014a). Identification and characterization of a novel splice site mutation in the SERPING1 gene in a family with hereditary angioedema. Clinical Immunology, This article is protected by copyright. All rights reserved. 
150(2),143-148. doi:10.1007/s10875-014-0042-3.

Colobran, R., Pujol-Borrell, R., Hernández-González, M., \& Guilarte, M. (2014b). A novel splice site mutation in the SERPING1 gene leads to haploinsufficiency by complete degradation of the mutant allele mRNA in a case of familial hereditary angioedema. Journal of Clinical Immunology, 34(5),521-523. doi:10.1007/s10875-014-0042-3.

Cumming, S. A., Halsall, D. J., Ewan, P. W., \& Lomas, D. A. (2003). The effect of sequence variations within the coding region of the $\mathrm{C} 1$ inhibitor gene on disease expression and protein function in families with hereditary angio-oedema. Journal of Medical Genetics, 40(10),e114. doi:10.1136/jmg.40.10.e114.

Davis, 3rd A. E., Aulak, K., Parad, R. B., Stecklein, H. P., Eldering, E., Hack, C. E., \& Rosen, F. S. (1992). C1 inhibitor hinge region mutations produce dysfunction by different mechanisms. Nature Genetics, 1(5),354-358.

Davis, A. E. (1997). C1 inhibitor. Functional analysis of naturally-occurring mutant proteins. Advances in Experimental Medicine and biology, 425,185-194.

Davis, A. E., Lu, F., Mejia, P. (2010). C1 inhibitor, a multi-functional serine protease inhibitor. Thrombosis and Haemostasis, 104(5),886-893. doi:10.1160/TH10-01-0073.

De la Cruz, R. M., López-Lera, A., \& López-Trascasa, M. (2011). Analysis of SERPING1 expression on hereditary angioedema patients: quantitative analysis of full-length and

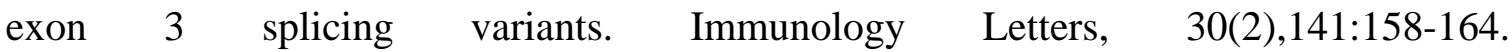
doi:10.1016/j.imlet.2011.07.011.

This article is protected by copyright. All rights reserved. 
Dijk, M., Holkers, J., Voskamp, P., Giannetti, B. M., Watarreus, W. J., van Veen, H. A., \& Pannu, N. S. (2016). How dextran sulphate affects C1-inhibitor activity: a model for polysaccharide potentiation. Structure, 6(12),2182-2189. doi:10.1016/j.str.2016.09.013.

Donaldson V. H., \& Bissler J. J. (1992). C1-inhibitors and their genes: an update. The Journal of Laboratory and Clinical Medicine, 119(4),330-333.

Drouet, C., Alibeu, C., Ponard, D., Arlaud, G. J., \& Colomb, M. G. (1988). A sensitive method to assay blood complement C1-inhibitor activity. Clinica et Chimica Acta, 174(2),121-130.

Duponchel, C., Di Rocco, C., Cicardi, M., \& Tosi, M. (2001). Rapid detection by fluorescent multiplex PCR of exon deletions and duplications in the C1 inhibitor gene of hereditary angioedema patients. Human Mutation, 17(1),61-70.

Duponchel, C., Djenouhat, K., Frémeaux-Bacchi, V., Monnier, N., Drouet, C., \& Tosi, M. (2006). Functional analysis of splicing mutations and of an exon 2 polymorphic variant of SERPING1/C1NH. Human Mutation, 27(3),295-296.

Ebo, D. E., Van Gasse, A. L., Sabato, V., Bartholomeus, E., Reyniers, E., Vanbellinghen, J.-F., ... Mortier G. (2018). Hereditary angioedema in 2 sisters due to paternal gonadal mosaicism. The Journal of Allergy and Clinical Immunology: In Practice, 6(1),277279.e1. doi.org/10.1016/j.jaip.2017.07.002.

Eldering, E., Huijbregts, C. C., Lubbers, Y. T., Longstaff, C., \& Hack, C. E. (1992). Characterization of recombinant C1 inhibitor P1 variants. The Journal of Biological Chemistry, 267(10),7013-7020.

This article is protected by copyright. All rights reserved. 
Eldering, E., Verpy, E., Roem, D., Meo, T., \& Tosi, M. (1995). COOH-terminal substitutions in the serpin C1 inhibitor that cause loop overinsertion and subsequent multimerization. The Journal of Biological Chemistry, 270(6),2579-2587.

El-Meguid, A. M., Aslanidis, C., Schimanski, S., Schambeck, C., Schmitz, G. (2008). New mutations in C1 esterase inhibitor (SERPING1) in a German family with hereditary angioedema. The Egyptian Journal of Immunology, 15(2),93-100.

Emonts, M., de Jongh, C. E., Houwing-Duistermaat, J. J., van Leeuwen, W. B., de Groot, R., Verbrugh, H. A., ... van Belkum, (2007). A. Association between nasal carriage of Staphylococcus aureus and the human complement cascade activator serine protease C1 inhibitor (C1INH) valine vs. methionine polymorphism at amino acid position 480 . FEMS Immunolology and Medical Microbiology, 50(3),330-332. doi: 10.1111/j.1574695X.2007.00250.X

Faiyaz-Ul-Haque, M., Al-Gazlan, S., Abalkhail, H. A., Al-Abdulatif, A., Toulimat, M., Peltekova, I., ... Zaidi, S. H. (2010). Novel and recurrent mutations in the C1NH gene of Arab patients affected with hereditary angioedema. International Archives of Allergy and Immunology, 151(2),149-154. doi:10.1159/000236005.

Farfara D, Feierman E, Richards A, Revenko, A. S., MacLeod, R. A., Norris, E. H., Strickland, S. (2019). Knockdown of circulating C1 inhibitor induces neurovascular impairment, glial cell activation, neuroinflammation, and behavioral deficits. Glia. 67(7),1359-1373. doi:10.1002/glia.23611.

This article is protected by copyright. All rights reserved. 
Ferraro, M. F., Moreno, A. S., Castelli, E. C., Donadi, E. A., Palma, M. S., Arcuri, H. A., ... Arruda, L. K. (2011). A single nucleotide deletion at the C1 inhibitor gene as the cause of hereditary angioedema: insights from a Brazilian family. Allergy, 66(10),1384-1390. doi:10.1111/j.1398-9995.2011.02658.

Firinu, D., Colomba, P., Manconi, P. E., Barca, M.P., Fenu, L., Piseddu, G., ... Duro, G. (2013). Identification of a novel and recurrent mutation in the SERPING1 gene in patients with hereditary angioedema. Clinical Immunology, 147(2),129-132. doi:10.1016/j.clim.2013.03.007.

Frangi, D., Cicardi, M., Sica, A., Colotta, F., Agostoni, A., Davis 3 ${ }^{\text {rd }}$, A. E. (1991). Nonsense mutations affect C1 inhibitor messenger RNA levels in patients with type I hereditary angioneurotic edema. The Journal of Clinical Investigation, 88(3),755-759.

Freiberger, T., Kolárová, L., Mejstrík, P., Vyskocilová, M., Kuklínek, P., \& Litzman, J. (2002). Five novel mutations in the C1inhibitor gene $(C 1 N H)$ leading to a premature stop codon in patients with type I hereditary angioedema. Human Mutatation, 19(4),461. doi:10.1002/humu.2029.

Germenis, A. E., \& Speletas, M. (2016). Genetics of hereditary angioedema revisited. Clinical Reviews in Allergy and Immunology, 51(2),170-182. doi:10.1007/s12016-0168543-X

Ghannam, A., Sellier, P., Defendi, F., Favier, B., Charignon, D., López-Lera, A., ... Drouet, C. (2015). C1 inhibitor function using contact-phase proteases as target: evaluation of an innovative assay. Allergy, 70(9),1103-1111. doi:10.1111/all.12657.

This article is protected by copyright. All rights reserved. 
Gibson, J., Hakobyan, S., Cree, A. J., Collins, A., Harris, C. L., Ennis, S., ... Lotery, A. J. (2012). Variation in complement component C1 inhibitor in age-related macular degeneration. Immunobiology, 217(2),251-255. doi:10.1016/j.imbio.2011.07.015.

Gößwein, T., Kocot, A., Emmert, G., Kreuz, W., Martinez-Saguer, I., Aygören-Pürsün, E., ... Müller, C. R. (2008). Mutational spectrum of the C1INH (SERPING1) gene in patients with hereditary angioedema. Cytogenetic and Genome Research, 121(3-4),181188. doi:10.1159/000138883.

Grivčeva-Panovska, V., Košnik, M., Korošec, P., Andrejević, S., Karadža-Lapić, L., \& Rijavec, M. (2018). Hereditary angioedema due to C1-inhibitor deficiency in Macedonia: clinical characteristics, novel SERPING1 mutations and genetic factors modifying the clinical phenotype. Annals of Medicine, 50(3),269-276. doi:10.1080/07853890.2018.1449959.

Grodecká, L., Hujová, P., Kramárek, M., Kršjaková, T., Kováčová, T., Vondrášková, K., ... Freiberger, T. (2017). Systematic analysis of splicing defects in selected primary immunodeficiencies-related genes. Clinical Immunology, 180,33-44. doi:10.1016/j.clim.2017.03.010.

Grymová, T., Grodecká, T., Souček, P., \& Freiberger, T. (2019). SERPING1 exon 3 splicing variants using alternative acceptor splice sites. Molecular Immunology, 107,9196. doi:10.1016/j.molimm.2019.01.007

This article is protected by copyright. All rights reserved. 
Guarino, S., Perricone, C., Guarino, M. D., Giardina, E., Gambardella, S., Rosaria D'Apice, M., ... Novelli, G. (2006). Gonadal mosaicism in hereditary angioedema. Clinical Genetics, 70(1),83-85. doi:10.1016/j.jaci.2007.05.041.

Han, E. D., MacFarlane, R. C., Mulligan, A. N., Scafidi, J., \& Davis III, A. E. (2002). Increased vascular permeability in C1 inhibitor-deficient mice mediated by the bradykinin type 2 receptor. The Journal of Clinical Investigation, 109(8):1057-1063. doi:10.1172/JCI14211.

Haslund, D., Ryø, L. B., Seidelin Majidi, S., Rose, I. K., Skipper, K. A., Fryland, T., ... Mikkelsen, J. G. (2019). Dominant negative SERPING1 variants cause intracellular retention of C1-inhibitor in hereditary angioedema. The Journal of Clinical Investigation, 129(1),388-405. doi:10.1172/JCI98869.

He, S., Yang, J. C., Tsang, S., Sim, R. B., \& Whaley, K. (1997). Role of the distal hinge region of C1-inhibitor in the regulation of C1s activity. FEBS Letters, 412(3),506-510.

Hofman, Z. L., Relan, A., Zeerleder, S., Drouet, C., Zuraw, B., \& Hack, C. E. (2016). Angioedema attacks in patients with hereditary angioedema: Local manifestations of a systemic activation process. The Journal of Allergy and Clinical Immunology, 138(2),359-366. doi:10.1016/j.jaci.2016.02.041.

Irving, J. A., Pike, R. N., Lesk, A. M., \& Whisstock, J. C. (2000). Phylogeny of the serpin superfamily: implications of patterns of amino acid conservation for structure and function. Genome Research, 10(12),1845-1864.

This article is protected by copyright. All rights reserved. 
Iwamoto, K., Tanaka, A., Kawai, M., Ishii, K., Mihara, S., \& Hide, M. (2012a). A large heterozygous deletion including the entire $C 1$ inhibitor gene in a sporadic case of hereditary angio-oedema. Clinical and Experimental Dermatology, 37(1),20-23. doi:10.1111/j.1365-2230.2011.04138.

Iwamoto, K., Tanaka, A., Hiragun, M., Kawai, M., Mihara, S., Takenaka, M., ... Hide, M. (2012b). Novel and recurrent C1 inhibitor gene mutations in nine Japanese patients with hereditary angioedema. Journal of Dermatological Science, 68(1),68-70. doi:10.1016/j.jdermsci.2012.06.012.

Jaradat, S. A., Caccia, S., Rawashdeh, R., Melhem, M., Al-Hawamdeh, A., Carzaniga, T., \& Haddad, H. (2016). Hereditary angioedema in a Jordanian family with a novel missense mutation in the C1-inhibitor N-terminal domain. Molecular Immunology, 71,123-130. doi:10.1016/j.molimm.2016.02.00.

Johnsrud, I., Kulseth, M. A., Rødningen, O. K., Landrø, L., Helsing, P., Waage Nielsen, E., \& Heimdal, K. (2015). A nationwide study of Norwegian patients with hereditary angioedema with C1 Inhibitor deficiency identified six novel mutations in SERPING1. PLoS One 10(7),10, e0131637. doi:10.1371/journal.pone.0131637.

Kalmár, L., Bors, A., Farkas, H., Vas, S., Fandl, B., Varga, L., ... Tordai, A. (2003). Mutation screening of the C1 inhibitor gene among Hungarian patients with hereditary angioedema. Human Mutation, 22(6),498. doi:10.1002/humu.9202.

This article is protected by copyright. All rights reserved. 
Kalmár, L., Hegedüs, T., Farkas, H., Nagy, M., \& Tordai, A. (2005). HAEdb: a novel interactive, locus-specific mutation database for the $\mathrm{C} 1$ inhibitor gene. Human Mutatation, 25(1),1-5. doi:10.1002/humu.20112.

Kang, H. R., Yim, E. Y., Oh, S. Y., Chang, Y. S., Kim, Y. K., Cho, S. H., ... Kim, Y. Y. (2006). Normal C1 inhibitor mRNA expression level in type I hereditary angioedema patients: newly found C1 inhibitor gene mutations. Allergy, 61(2),260-264. doi:10.1111/j.1398-9995.2006.01010.

Karadža-Lapić, L., Korošec, P., Šilar, M., Košnik, M., Cikojević, D., Lozić, B., \& Rijavec, M. (2016). Frequent life-threatening laryngeal attacks in two Croatian families with hereditary angioedema due to C1 inhibitor deficiency harbouring a novel frameshift mutation in SERPING1. Annals of Medicine, 48(7),485-491. doi:10.1080/07853890.2016.1185144.

Kasamatsu, Y., Yoshinoya, K., Kasamatsu, Y., Yamamoto, T., Horiuchi, T., \& Kadoya, M. (2011). A case of hereditary angioedema involving recurrent abdominal attacks. Internal Medicine, 50(23),2911-2914. doi:10.2169/internalmedicine.50.6224.

Kawachi, Y., Hibi, T., Yamazaki, S., \& Otsuka, F. (1998). A novel donor splice site mutation in the $C 1$ inhibitor gene of a patient with type I hereditary angioneurotic edema. The Journal of Investigative Dermatology, 110(5),837-839. doi:10.1046/j.15231747.1998.00170.

Kesim, B., Uyguner, Z. O., Gelincik, A., Mete Gökmen, N., Sin, A. Z., Karakaya, G.,... Büyüköztürk, S. (2011). The Turkish Hereditary Angioedema Pilot Study (TURHAPS):

This article is protected by copyright. All rights reserved. 
the first Turkish series of hereditary angioedema. International Archives of Allergy and Immunology, 156(4),443-450. doi:10.1159/000323915.

Klausegger, A., Wiednig, M., Urban, C., Lackner, H., Reiter, H., Bauer, J. W., \& Aberer, W. (2012). Successful allogeneic cord blood transplantation in a patient with Evans syndrome leads to correction of hereditary angioedema type I as secondary effect. Bone Marrow Transplantation, 47(9),1259-1261. doi:10.1038/bmt.2012.7.

Kozlowski, P., Jasinska, A. J., \& Kwiatkowski, D. J. (2008). New applications and developments in the use of multiplex ligation-dependent probe amplification. Electrophoresis, 29(23),4627-4636. doi:10.1002/elps.200800126.

Kralovicova, J., \& Vorechovsky, I. (2009). SERPING1 rs2511988 and age-related macular degeneration. Lancet, 373(9662),461-462. doi:10.1016/S0140-6736(09)60168-9.

Krishnan, B., \& Gierasch, L. M. (2011). Dynamic local unfolding in the serpin $\alpha-1$ antitrypsin provides a mechanism for loop insertion and polymerization. Nature Structural and Molecular Biology, 18(22),222-226. doi:10.1038/nsmb.1976

Laimer, M., Klausegger, A., Aberer, W., Oender, K., Steinhuber, M., Lanschuetzer, C. M., ... Bauer, J. W. (2006). Haploinsufficiency due to deletion within the 3'-UTR of C1INH-gene associated with hereditary angioedema. Genetics in Medicine, 8(4),249-254. doi:10.1097/01.gim.0000214302.90076.fa.

Levy, N. J., Ramesh, N., Cicardi, M., Harrison, R. A., \& Davis III, A. E. (1990). Type II hereditary angioedema that may result from a single nucleotide change in the codon for

This article is protected by copyright. All rights reserved. 
alanine-436 in the C1 inhibitor gene. Proceedings of the National Academy of Sciences of the United States of America, 87(1),265-268.

Lomas, D. A., Belorgey, D., Mallya, M., Miranda, E., Kinghorn, K. J., Sharp, L. K., ... Crowther, D. C. (2005). Molecular mousetraps and the serpinopathies. Biochemical Society Transactions, 33(Pt2),321-330. doi:10.1042/BST0330321.

López-Lera, A., Favier, B., de la Cruz, R.M., Garrido, S., Drouet, C., \& López-Trascasa, M. (2010). A new case of homozygous C1-Inhibitor deficiency suggests a role for Arg378 in the control of kinin pathway activation. The Journal of Allergy and Clinical Immunology, 126(6),1307-1310. doi:10.1016/j.jaci.2010.07.037.

López-Lera, A., Garrido, S., Roche, O., \& López-Trascasa, M. (2011). SERPING1 mutations in 59 families with hereditary angioedema. Molecular Immunology, 49(12),18-27. doi:10.1016/j.molimm.2011.07.010.

López-Lera, A., Cabo, F. S., Garrido, S., Dopazo, A., \& López-Trascasa, M. (2013). Disease-modifying factors in hereditary angioedema: an RNA expression-based screening. Orphanet Journal of Rare Diseases, 8,77. doi:10.1186/1750-1172-8-77.

Loules, G., Zamanakou, M., Parsopoulou, F., Vatsiou, S., Psarros, F., Csuka, D., ... Germenis, A. E. (2018). Targeted next-generation sequencing for the molecular diagnosis of hereditary angioedema due to C1-inhibitor deficiency. Gene, 667,76-82. doi:10.1016/j.gene.2018.05.029.

This article is protected by copyright. All rights reserved. 
Lu, F., Zhao, P., Fan, Y., Tang, S., Hu, J., Liu, X., ... Yang, Z. (2010). An association study of SERPING1 gene and age-related macular degeneration in a Han Chinese population. Molecular Vision, 16,1-6.

Maaser, A., Forstner, A.J., Strohmaier, J., Hecker, J., Ludwig, K. U., Sivalingam S., ... Nöthen, M.M. (2018). Exome sequencing in large, multiplex bipolar disorder families from Cuba. PLoS One, 13(10),e0205895. doi:10.1371/journal.pone.0205895.

Maia, L. S. M., Moreno, A. S., Ferriani, M. P. L., Nunes, F. L., Ferraro, M. F., Dias, M. M., ... Arruda, L. K. (2019). Genotype-phenotype correlations in Brazilian patients with hereditary angioedema due to C1 inhibitor deficiency. Allergy, 74(5),1013-1016. doi:10.1111/all.13699.

Martinho, A., Mendes, J., Simões, O., Nunes, R., Gomes, J., Dias Castro, E., ... Pais, L. (2013). Mutations analysis of C1 inhibitor coding sequence gene among Portuguese patients with hereditary angioedema. Molecular Immunology, 53(4),431-434. Doi:10.1016/j.molimm.2012.09.003.

Madsen, D. E., Hansen, S., Gram, J., Bygum, A., Drouet, C., \& Sidelmann, J. J. (2014). Presence of C1-inhibitor polymers in a subset of patients suffering from hereditary angioedema. PLoS One, 9(11),e112051. doi:10.1371/journal.pone.0112051.

Madsen, D. E., Sidelmann, J. J., Biltoft, D., Gram, J., \& Hansen, S. (2015). C1-inhibitor polymers activate the FXII-dependent kallikrein-kinin system: Implication for a role in hereditary angioedema. Biochimica et Biophysica Acta, 1850(6),1336-1342. doi:10.1016/j.bbagen.2015.03.005.

This article is protected by copyright. All rights reserved. 
Maurer, M., Magerl, M., Ansotegui, I., Aygören-Pürsün, E., Betschel, S., Bork, K., ... Craig, T. 2018. The international WAO/EAACI guideline for the management of hereditary angioedema-The 2017 revision and update. Allergy, 73(8),1393-1414. doi:10.1111/all.13384.

McPhaden, A. R., Birnie, G. D., \& Whaley, K. (1991). Restriction fragment length polymorphism analysis of the C1-inhibitor gene in hereditary C1-inhibitor deficiency. Clinical Genetics, 39(3),161-71.

Mete Gökmen, N., Gülbahar, O., Onay, H., Peker Koc, Z., Özgül, S., Köse, T., ... Sin, A. Z. (2019). Deletions in SERPING1 lead to lower C1 Inhibitor function: lower C1 Inhibitor function can predict disease severity. International Archives of Allergy and Immunology, 2(1),1-10. doi:10.1159/000492583.

Monnier, N., Ponard, D., Duponchel, C., Csopaki, F., Bouillet, L., Tosi, M., ... Drouet, C. (2006). Characterisation of a new C1 inhibitor mutant in a patient with hepatocellular carcinoma. Molecular Immunology, 43(14),2161-2168. doi:10.1016/j.molimm.2006.01.006.

Nicolicht, P., Faria, D. O. S., Martins-Silva, L., Maia, L. S. M., Moreno, A. S., Arruda, L. K., ... Pesquero, J. B. (2019). Gene mapping strategy for Alu elements rearrangements: Detection of new large deletions in the SERPING1 causing hereditary angioedema in Brazilian families. Gene, 685,179-185. doi:10.1016/j.gene.2018.10.084.

This article is protected by copyright. All rights reserved. 
Oschatz, C., Maas, C., Lecher, B., Jansen, T., Björkvist, J., Tradler, T., ... Renné, T. (2001). Mast cells increase vascular permeability by heparin-initiated bradykinin formation in vivo. Immunity, 34(2), 258-268. doi:10.1016/j.immuni.2011.02.008

Ocejo-Vinyals, J. G., Leyva-Cobián, F., \& Fernández-Luna, J. L. (1995). A mutation unique in serine protease inhibitors (serpins) identified in a family with type II hereditary angioneurotic edema. Molecular Medicine, 1(6),700-705.

Ono, H., Kawaguchi, H., Ishii, N., \& Nakajima, H. (1996). A point mutation in exon 7 of the C1-inhibitor gene causing type I hereditary angioedema. Human Genetics, 98(4),452453.

Otani, T., Hoshika, S., Horiuchi, T., Hashimura, C., \& Sugihara, S. (2019). Hereditary angioedema: Repeated attacks in a 10-year-old boy. Pediatrics International, 61(1),101103. doi:10.1111/ped.13729.

Papadopoulou-Alataki, E., Foerster, T., Antari, V., Pavlitou-Tsiontsi, A., \& Varlamis, G. (2008). Molecular diagnosis and management of hereditary angioedema in a Greek family. International Archives of Allergy and Immunology, 147(2),166-170. doi:10.1159/000137286.

Pappalardo, E., Cicardi, M., Duponchel, C., Carugati, A., Choquet, S., Agostoni, A., \& Tosi, M. (2000). Frequent de novo mutations and exon deletions in the C1inhibitor gene of patients with angioedema. The Journal of Allergy and Clinical Immunology, 106(6),1147-1154. doi:10.1067/mai.2000.110471.

This article is protected by copyright. All rights reserved. 
Pappalardo, E., Caccia, S., Suffritti, C., Tordai, A., Zingale, L., \& Cicardi, M. (2008). Mutation screening of C1 inhibitor gene in 108 unrelated families with hereditary angioedema: functional and structural correlates. Molecular Immunology, 45(13),35363544. doi:10.1016/j.molimm.2008.05.00.

Park, K. H., Ryu, E., Tosakulwong, N., Wu, Y., \& Edwards, A. O. (2009). Common variation in the SERPING1 gene is not associated with age-related macular degeneration in two independent groups of subjects. Molecular Vision, 15:200-207.

Patston, P. A., Hauert, J., Michaud, M., \& Schapira, M. (1995). Formation and properties of C1-inhibitor polymers. FEBS Letters, 368(3),401-404.

Pedrosa, M., Phillips-Angles, E., López-Lera, A., López-Trascasa, M., \& Caballero, T. (2016). Complement study versus CINH gene testing for the diagnosis of type I hereditary angioedema in children. Journal of Clinical Immunology, 36(1),16-18. doi:10.1007/s10875-015-0222-9.

Qiu, T., Chiuchiolo, M. J., Whaley, A. S., Russo, A. R., Sondhi, D., Kaminsky, S. M., ... Pagovich, O. E. (2019). Gene therapy for C1 esterase inhibitor deficiency in a murine model of hereditary angioedema. Allergy, , 74(6):1081-1089. doi:10.1111/all.13582.

Qu, L., Wei, B., Liu, M., Zhang, L., Xiao, T., Chen H. D., ... He, C. (2012). A novel mutation in exon 8 of $\mathrm{C} 1$ inhibitor (C1INH) gene leads to abolish its physiological stop codon in a large Chinese family with hereditary angioedema type I. Experimental Dermatology, 21(10),788-791. doi:10.1111/j.1600-0625.2012.01563.

This article is protected by copyright. All rights reserved. 
Rijavec, M., Korošec, P., Šilar, M., Zidarn, M., Miljković, J., \& Košnik, M. (2013). Hereditary angioedema nationwide study in Slovenia reveals four novel mutations in SERPING1 gene. PLoS One, 8(2),e56712. doi:10.1371/journal.pone.0056712.

Roche, O., Blanch, A., Duponchel, C., Fontán, G., Tosi, M., \& López-Trascasa, M. (2005). Hereditary angioedema: the mutation spectrum of SERPING1/C1NH in a large Spanish cohort. Human Mutation, 26(2),135-144. doi:10.1002/humu.20197.

Rodríguez, J. A., \& Narváez, C. F. (2018). First analysis of SERPING1 gene in patients with hereditary angioedema in Colombia reveals two genotypic variants in a highly symptomatic individual. Journal of Clinical Immunology, 38(3), 294-299. doi:10.1007/s10875-018-0491-1.

Rosen, F. S., Pensky, J., Donaldson, V., \& Charache, P. (1965). Hereditary angioneurotic edema: Two genetic variants. Science, 148(3672),957-958.

Rossi, V., Bally, I., Ancelet, S., Xu, Y., Frémeaux-Bacchi, V., Vivès, R. R., ... Arlaud, G. J. (2010). Functional characterization of the recombinant human C1 inhibitor serpin domain: insights into heparin binding. The Journal of Immunology, 184(9),4982-4989. doi: 10.4049/jimmunol.0902016.

Schizophrenia Working Group of the Psychiatric Genomics Consortium. (2014). Biological insights from 108 schizophrenia-associated genetic loci. Nature, 511(7510),421-427. doi:10.1038/nature13595.

This article is protected by copyright. All rights reserved. 
Schwarz, J. M., Cooper, D. N., Schuelke, M., \& Seelow, D. (2014). MutationTaster2: mutation prediction for the deep-sequencing age. Nature Methods, 11(4), 361-362. doi:10.1038/nmeth.2890.

Sekijima, Y., Hashimoto, T., Kawashi, Y., Koshihara, H., Otsuka, F., \& Ikeda, S.-I. (2004). A novel mRNA splice site mutation in the C1 inhibitor gene of a patient with type I hereditary angioedema. Internal Medicine, 43(3),253-255. doi:10.2169/internalmedicine.43.253.

Siddique, Z., McPhaden, A. R., Lappin, D. F., \& Whaley, K. (1991). An RNA splice site mutation in the C1-inhibitor gene causes type I hereditary angio-oedema. Human Genetics, 88(2),231-232.

Siddique, Z., · McPhaden A. R., · McCluskey, D., · \& Whaley K. (1992a). A single base deletion from the C1-inhibitor gene causes type I hereditary angio-oedema. Human Heredity, 42(4),231-234.

Siddique, Z., McPhaden, A. R., \& Whaley, K. (1992b). Type II hereditary angio-oedema associated with two mutations in one allele of the C1-inhibitor gene around the reactivesite coding region. Human Heredity, 42(5),298-301.

Siddique, Z., McPhaden, A. R., Fothergill, J. E., \& Whaley, K. (1993a). A point mutation in the C1-inhibitor gene causes type I hereditary angiooedema. Human Heredity, 43(3),155-158.

Siddique, Z., McPhaden, A. R., \& Whaley, K. (1993b). C1-inhibitor gene nucleotide insertion causes type II hereditary angio-oedema. Human Genetics, 92(2),189-190.

This article is protected by copyright. All rights reserved. 
Siddique, Z., McPhaden, A. R., \& Whaley, K. (1995). Characterisation of nucleotide sequence variants and disease-specific mutations involving the 3' end of the C1-inhibitor gene in hereditary angio-oedema. Human Heredity, 45(2),98-102.

Sim, N. L., Kumar, P., Hu, J., Henikoff, S., Schneider, G., \& Ng, P.C. (2012). SIFT web server: predicting effects of amino acid substitutions on proteins. Nucleic Acids Research, 40(web server issue),W452-457. doi:10.1093/nar/gks539.

Sim, D. W., Park, K. H., Lee, J.-H., \& Park, J.-W. (2017). A case of type II hereditary angioedema with SERPING1 mutation. Allergy Asthma and Immunology Research, 9(1),96-98. doi:10.4168/aair.2017.9.1.96.

Skriver, K., Radziejewska, E., Silbermann, J. A., Donaldson, V. H., \& Bock, S. C. (1989). CpG mutations in the reactive site of human C1 inhibitor. The Journal of Biological Chemistry, 264(6),3066-3071.

Skriver, K., Wikoff, W. R., Patston, P. A., Tausk, F., Schapira, M., Kaplan, A. P., \& Bock, S. C. (1991). Substrate properties of C1 Inhibitor Ma (alanine 434>glutamic acid). Genetic and structural evidence suggesting that the P12-region contains critical determinants of serine protease inhibitor/substrate status. The Journal of Biological Chemistry, 266(14), 9216-9221.

Speletas, M., Szilagyi, A., Psarros, F., Moldovan, D., Magerl, M., Kompoti, M., ... Germenis, A. E. (2015a). Hereditary angioedema: molecular and clinical differences among European populations. The Journal of Allergy and Clinical Immunology, 135(2),570-573. doi:10.1016/j.jaci.2014.08.007.

This article is protected by copyright. All rights reserved. 
Speletas, M., Szilágyi, Á., Csuka, D., Koutsostathis, N., Psarros, F., Moldovan, D., ... Germenis, A. E. (2015b). F12-46C/T polymorphism as modifier of the clinical phenotype of hereditary angioedema. Allergy, 70(12),1661-1664. doi:10.1111/all.12714.

Stein, P. E., \& Carrell, R. W. (1995). What do dysfunctional serpins tell us about molecular mobility and disease. Nature Structural Biology, 2(2),96-113.

Steiner, U., Keller, M., Schmid, P., Cichon, S., \& Wuillemin, W. A. (2017). Mutational spectrum of the SERPING1 gene in Swiss patients with Hereditary Angioedema. Clinical and Experimental Immunology, 188(3),430-436. doi:10.1111/cei.12941.

Stenson, P. D., Mort, M., Ball, E. V., Evans, K., Hayden, M., Heywood, S., ... Cooper, D. N. (2017). The Human Gene Mutation Database: towards a comprehensive repository of inherited mutation data for medical research, genetic diagnosis and next-generation sequencing studies. Human Genetics, 136(6),665-677. doi:10.1007/s00439-017-1779-6.

Stoppa-Lyonnet, D., Tosi, M., Laurent, J., Sobel, A., Lagrue, G., \& Meo T. (1987). Altered C1 inhibitor genes in type I hereditary angioedema. The New England Journal of Medicine, 317(1),1-6.

Stoppa-Lyonnet, D., Carter, P. E., Meo, T., \& Tosi, M. (1990). Clusters of intragenic Alu repeats predispose the human C1 inhibitor locus to deleterious rearrangements. Proceedings of the National Academy of Sciences of the United States of America, 87(4),1551-1555.

Stoppa-Lyonnet, D., Duponchel, C., Meo, T., Laurent, J., Carter, P. E., Arala-Chaves, M., ... Tosi, M. (1991). Recombinational biases in the rearranged C1-inhibitor genes of This article is protected by copyright. All rights reserved. 
hereditary angioedema patients. American Journal of Human Genetics, 49(49),10551062.

Suffriti, C., Zanichelli, A., Maggioni, L., Bonanni, E., Cugno, M., \& Cicardi, M. (2014). High-molecular-weight kininogen cleavage correlates with disease states in the bradykinin-mediated angioedema due to hereditary C1-inhibitor deficiency. Clinical and Experimental Allergy, 44(12),1503-1514. doi:10.1111/cea.12293.

Sugiyama, E., Ozawa, T., Taki, H., Maruyama, M., Yamashita, N., Ohta M., ... Kobayashi, M. (2001). Hereditary angioedema with a de novo mutation of exon 8 in the C1 Inhibitor gene showing recurrent edema of the hands around the peripheral joints. Arthritis and Rheumatism, 44(4),974-977. Doi:10.1002/15290131(200104)44:4<974::AID-ANR155>3.0.CO;2-1.

Tang, R., \& Zhang, H. Y. (2009). Newly found C1 inhibitor gene mutation in hereditary angioedema patients. Chinese Medical Sciences Journal, 24(4),252.

Tarzi, M. D., Hickey, A., Förster, T., Mohammadi, M., \& Longhurst, H. J. (2007). An evaluation of tests used for the diagnosis and monitoring of C1 inhibitor deficiency: normal serum C4 does not exclude hereditary angio-oedema. Clinical and Experimental Immunology, 149(3),513-516. doi:10.1111/j.1365-2249.2007.03438.

Tsutsui, Y., Dela Cruz, R., \& Wintrode, P. L. (2012). Folding mechanism of the metastable serpin $\alpha 1$-antitrypsin. Proceedings of the National Academy of Sciences of the United States of America, 109(12),4467-4472. doi:10.1073/pnas.1109125109.

This article is protected by copyright. All rights reserved. 
Uyguner, Z. O., \& Kesim, B. E. (2008). SERPING1: angioneurotic edema. Human Genetics, 124(3),308-310.

Veronez, C. L., Dias da Silva, E., Teixeira, P. V. L., Cagini, N., Constantino-Silva, R. N., Grumach, A. S., \& Pesquero, J. B. (2016). Genetic analysis of hereditary angioedema in a Brazilian family by targeted next generation sequencing. Biological Chemistry, 397(4),315-322. doi:10.1515/hsz-2015-0212

Verpy, E., Couture-Tosi, E., Eldering, E., López-Trascasa, M., Späth, P., Meo, T., \& Tosi, M. (1995). Crucial residues in the carboxy-terminal end of C1 inhibitor revealed by pathogenic mutants impaired in secretion or function. The Journal of Clinical Investigation, 95(1),350-359.

Verpy, E., Biasotto, M., Brai, M., Misiano, G., Meo, T., \& Tosi, M. (1996). Exhaustive mutation scanning by fluorescence-assisted mismatch analysis discloses new genotypephenotype correlations in angioedema. American Journal of Human Genetics, 59(2),308319.

Wang, Z., \& Burge, C. B. (2008). Splicing regulation: from a parts list of regulatory elements to an integrated splicing code. RNA, 14(5),802-813. doi:10.1261/rna.876308.

Wen, D. C., Shyur, S. D., Wu, J. Y., Lin, C. C., Chiang, Y. C., Huang, L. H., ... Liang, P. H. (2007). Hereditary angioedema: a Taiwanese family with a novel gene mutation. Asian Pacific Journal of Allergy and immunology, 25(2-3),163-167.

This article is protected by copyright. All rights reserved. 
Wong, W.-Y., Wong, H., Au, E., \& Chan, E. (2019). Identification and mapping of a 2,009-bp DNA deletion in SERPING1 of a hereditary angioedema patient. Case Reports in Genetics, 2019:7052062. doi:10.1155/2019/7052062.

Woo, P., Lachmann, P. J., Harrison, R. A., Amos, N., Cooper, C., \& Rosen, F. S. (1985). Simultaneous turnover of normal and dysfunctional C1 inhibitor as a probe of in vivo activation of $\mathrm{C} 1$ and contact activatable proteases. Clinical and Experimental Immunology, 61(1),1-8.

Wuillemin, W. A., Eldering, E., Citarella, F., de Ruig, C. P., ten Cate, H., \& Hack, C. E. (1996). Modulation of contact system proteases by glycosaminoglycans. Selective enhancement of the inhibition of factor XIa. The Journal of Biological Chemistry, 271(22),12913-12918.

Xu, Y. Y., Zhi, Y. X., Yin, J., Wang, L. L., Wen, L. P., Gu, J. Q., ... Zhang, H. Y. (2012). Mutational spectrum and geno-phenotype correlation in Chinese families with hereditary angioedema. Allergy, 67(11),1430-1436. doi:10.1111/all.12024.

Xu, X., Yang, X., Wu, Q., Liu, A., Yang, X., Ye, A. Y., ... Zhang, Y. (2015). Amplicon resequencing identified parental mosaicism for approximately $10 \%$ of 'de novo' SCN1A mutations in children with Dravet syndrome. Human Mutation, 36(9),861-872. doi:10.1002/humu.22819.

Xu, Y. Y., \& Zhi, Y. X. (2018). A compound mutation (c.953C $<\mathrm{G}$ and c.49G $<$ A) aggravates functional impairments of C1-INH in Hep G2 cells. Allergy Asthma and Immunology Research, 10(3),285-286. doi:10.4168/aair.2018.10.3.285.

This article is protected by copyright. All rights reserved. 
Yakushiji, Y., Mizuta, H., Kurohara, K., Onoue, H., Okada, R., Yoshimura, T., \& Kuroda, Y. (2007). Vasculitic neuropathy in a patient with hereditary C1 Inhibitor deficiency. Archives of Neurology, 64(5),731-733. doi:10.1001/archneur.64.5.731.

Yakushiji, H., Kaji, A., Suzuki, K., Yamada, M., Horiuchi, T., \& Sinozaki, M. (2016). Hereditary angioedema with recurrent abdominal pain in a patient with a novel mutation. Internal Medicine, 55(19),2885-2887. doi:10.2169/internalmedicine.55.6951.

Yamamoto, T., Horiuchi, T., Miyahara, H., Yoshizawa, S., Maehara, J., Shono, E., ... Akashi, K. (2012). Hereditary angioedema in Japan: genetic analysis of 13 unrelated cases. The American Journal of the Medical Sciences, 343(3),210-214. doi:10.1097/MAJ.0b013e31822bdb65.

Yu, T.-C., Shyur, S.-D., Huang, L.-H., Wen, D.-C., \& Li, J.-S. (2007). Paternal mosaicism and hereditary angioedema in a Taiwanese family. Annals of Allergy, Asthma and Immunology, 99(4),375-379. doi:10.1016/S1081-1206(10)60557-1.

Zahedi, R., Bissler, J. J., Davis III, A. E., Andreadis, C., \& Wisnieski, J. J. (1995). Unique C1 inhibitor dysfunction in a kindred without angioedema. II. Identification of an Ala443 $>$ Val substitution and functional analysis of the recombinant mutant protein. The Journal of Clinical Investigation, 95(3),1299-1305.

Zahedi, R., Aulak, K. S., Eldering, E., \& Davis $3^{\text {rd }}$, A. E. (1996). Characterization of C1 inhibitor-Ta. A dysfunctional C1INH with deletion of lysine 251. The Journal of Biological Chemistry, 271(39),24307-24312.

This article is protected by copyright. All rights reserved. 
Zahedi, R., Wisnieski, J., \& Davis III, A. E. (1997). Role of the P2 residue of complement 1 inhibitor (Ala443) in determination of target protease specificity: inhibition of complement and contact system proteases. Journal of Immunology, 159(2),983-988.

Zhi, Y. X., Zhang, H. Y., \& Huang, S. Z. (2003). [Identification of a novel mutation of C1 inhibitor gene in a Chinese family with hereditary angioedema]. Zhongguo Yi Xue Ke Xue Yuan Xue Bao, 25(6),664-666. [Article in Chinese]

Zuraw, B. L., \& Herschbach, J. (2000). Detection of C1 inhibitor mutations in patients with hereditary angioedema. The Journal of Allergy and Clinical Immunology, 105(3),541-546. doi:10.1067/mai.2000.104780.

Repository of novel variants. According to the Author Guidelines, novel variants $(n=120)$ have been successfully introduced at Global Variome shared LOVD; URL https://databases.lovd.nl/shared/individuals/SERPING1 according to the Author Guidelines.

\section{Figures}

FIGURE 1. Crucial regions ascribed to C1 Inhibitor (C1Inh) Serpin function. A. Schematic representation of secreted C1Inh. Residue numbering conforms to the mature protein; post-translational modifications and corresponding mRNA are shown. Branched symbols, $N$-glycosylation $(\mathrm{n}=6)$; black circles, verified $O$-glycosylation sites $(\mathrm{n}=7)$; gray circles, potential $O$-glycosylation $(n=7)$. S-S, disulfide bonds $(n=2)$. B. Overall structure of native C1Inh serpin domain, with the position of exemplary variants

This article is protected by copyright. All rights reserved. 
described in Table 1 shown with side-chains in sticks. Five regions for the serpin function are presented on the 3D-model of C1Inh (PDB ID 5DU3; [Dijk et al., 2016]) presented using Pymol. The model starts at $\mathrm{Phe}^{100}$ and lacks a great part of the N-terminal domain (residues 1-112). Strategic functional regions [Stein and Carrell, 1995] are indicated with (i) the reactive site loop (RCL), coloured purple, including $\operatorname{Arg}^{444} \mathrm{P} 1$ and the hinge region (P15-P9), essential for protease recognition and RCL mobility and conformational transformation for its insertion as strand 4A (s4A), ie. S $>\mathrm{R}$ transition, after protease inhibition; (ii) the central $\beta$-sheet $A$, coloured red, with the breach region, located at its top and point of initial insertion of RCL, and the shutter domain, coloured dark blue, close to the centre of $\beta$-sheet A, that, with breach, assists sheet opening and accepts the insertion of conserved proximal hinge s4A between s3A and s5A; (iii) the gate, highlighted with green sticks, including s3C and $\mathrm{s} 4 \mathrm{C}$ of $\beta$-sheet $\mathrm{C}$. $\beta$-sheets $\mathrm{B}$ and $\mathrm{C}$ are coloured green and brown, respectively. Examples of SERPING1 gene variants, mostly associated with the types II or intermediate, are indicated. C. Overall structure of the latent form of C1Inh. The same regions involved in the serpin function and examples of variants depicted in Figure 1B are presented on the 3D-model (PDB ID 20AY [Beinrohr et al., 2007]). D. Native form. Zoom showing the position of SERPING1 variants in proximity to the areas involved in RCL insertion. Representative breach and shutter residues are labelled cyan and dark blue, respectively. Variant positions listed in Table 1 are framed in magenta, green and orange according to class I, II and III, respectively. E. Latent form. Zoom showing the same positions.

This article is protected by copyright. All rights reserved. 
A
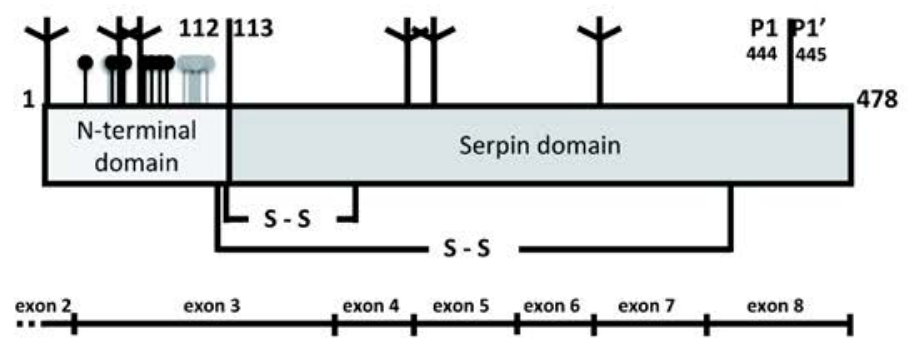

B

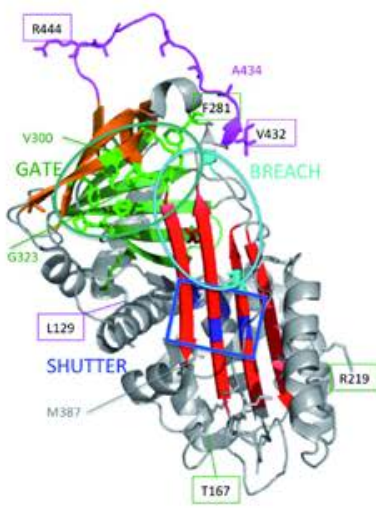

Native

D

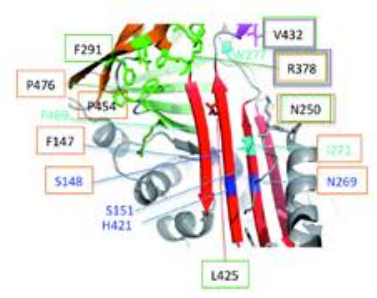

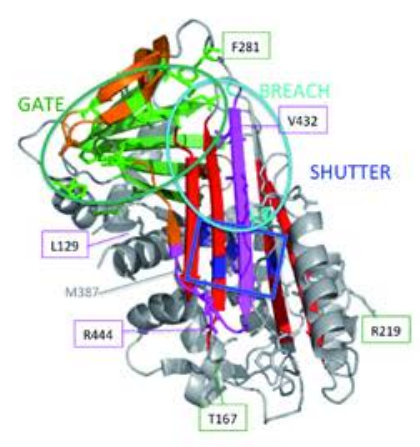

Latent

E

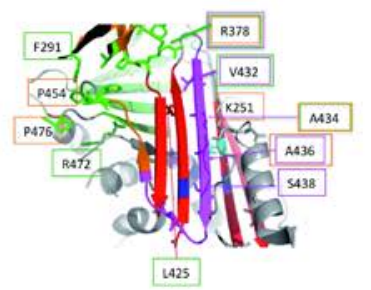

This article is protected by copyright. All rights reserved. 
FIGURE 2. Non-polymorphic SERPING1 variants distributed by variant type $(\mathrm{n}=748)$. The overall SERPING1 variants are compiled in Supp. Tables S1-5 according to specific variant groups and may be found online in the Supporting information. Two stop-loss variants have been included into the missense group.

\section{Figure 2}

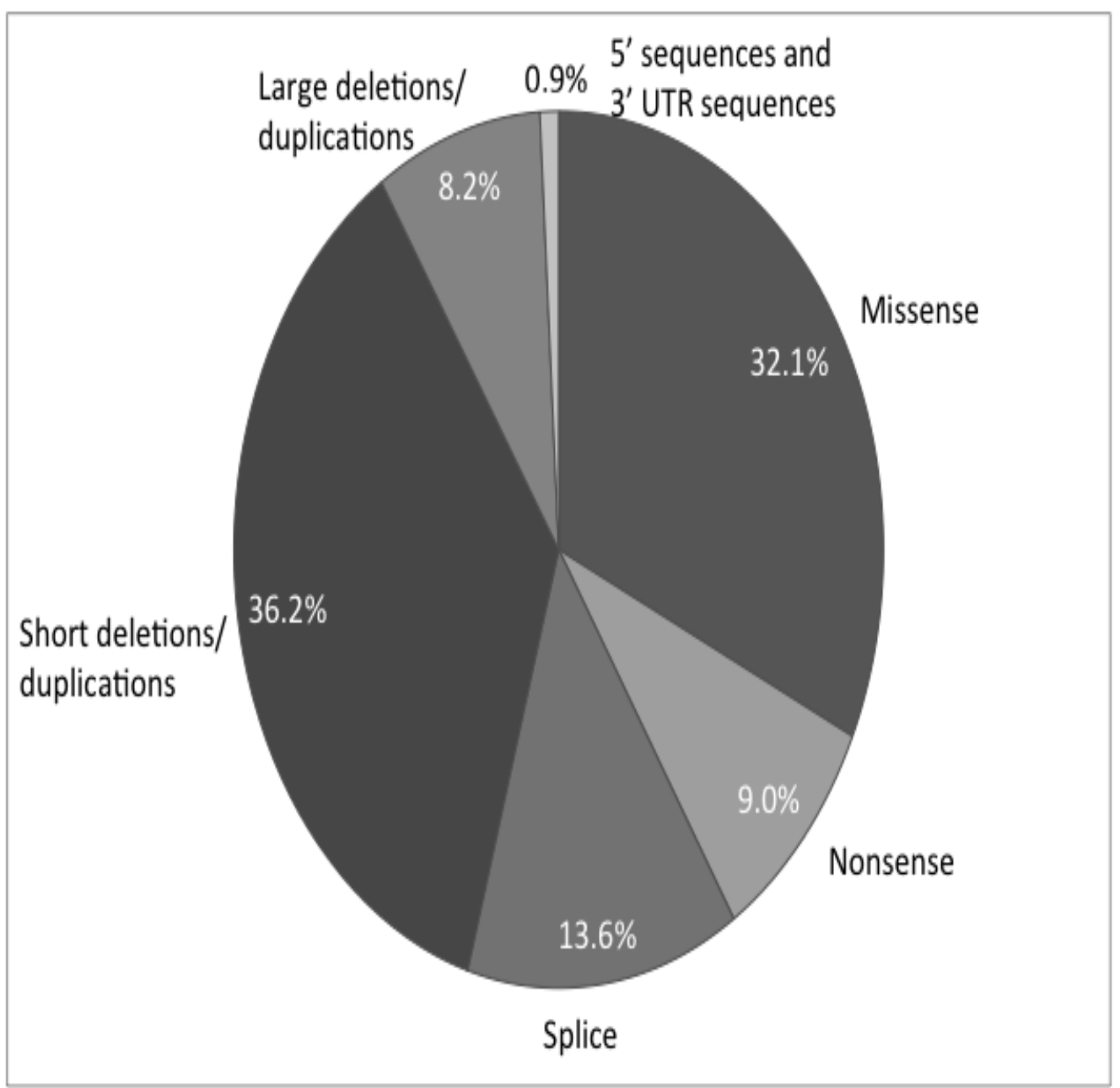

This article is protected by copyright. All rights reserved. 
FIGURE 3. Circulating C1 Inhibitor (C1Inh) molecular species demonstrated by antiC1Inh immunoblot. Plasma samples were collected from patients presenting with hereditary angioedema with C1Inh deficiency (regardless of whether during attack or remission period). The values of the corresponding antigenic C1Inh and C1Inh function assay using C1s protease or contact phase as targets are indicated for every individual. C1Inh, C1 Inhibitor; +C1s, addition of 0.1nM C1s protease to the sample followed by 15min incubation at $37^{\circ} \mathrm{C}$.

This article is protected by copyright. All rights reserved. 
Figure 3

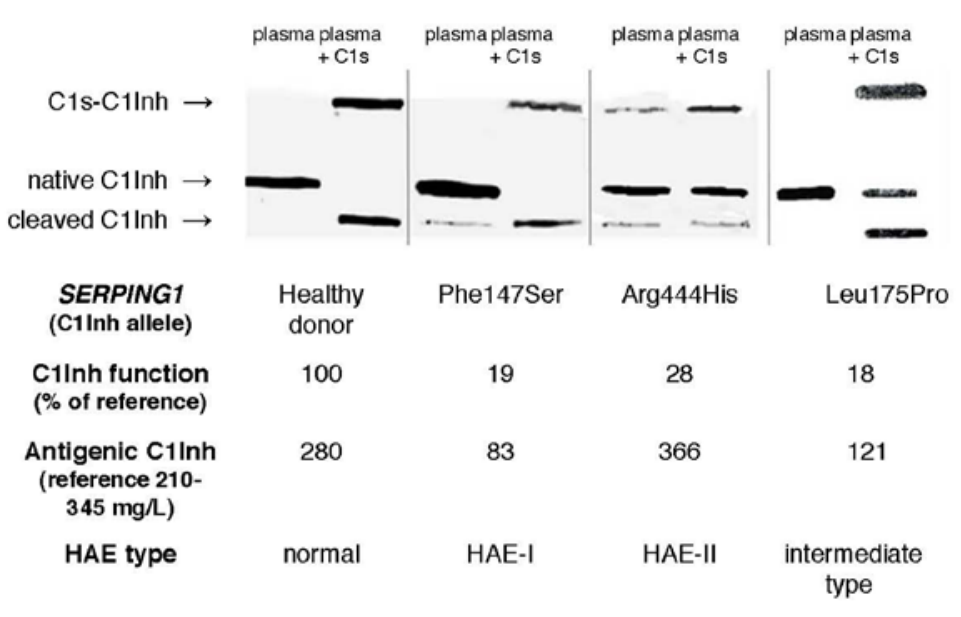

This article is protected by copyright. All rights reserved. 
FIGURE 4. Distribution of variants associated with C1-INH-HAE of type II (panel A) and of intermediate type (panel B) in the SERPING1 gene. Exons are numbered 1 to 8 and are drawn to scale in blue, with coding sequence in dark blue. The main protein domains are indicated in green. The reactive site loop (RCL) is indicated. Missense variants associated with intermediate type and type II are distributed according to their mature protein numbering.

Figure 4

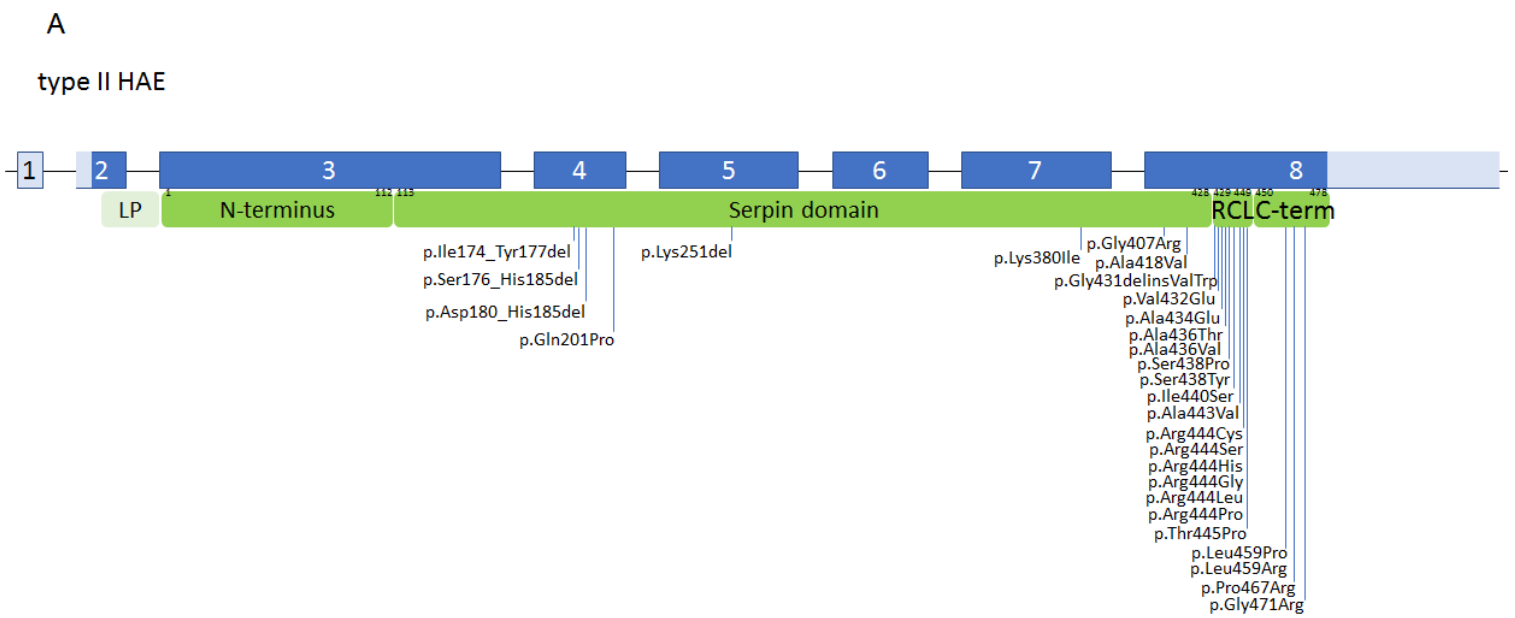

This article is protected by copyright. All rights reserved. 


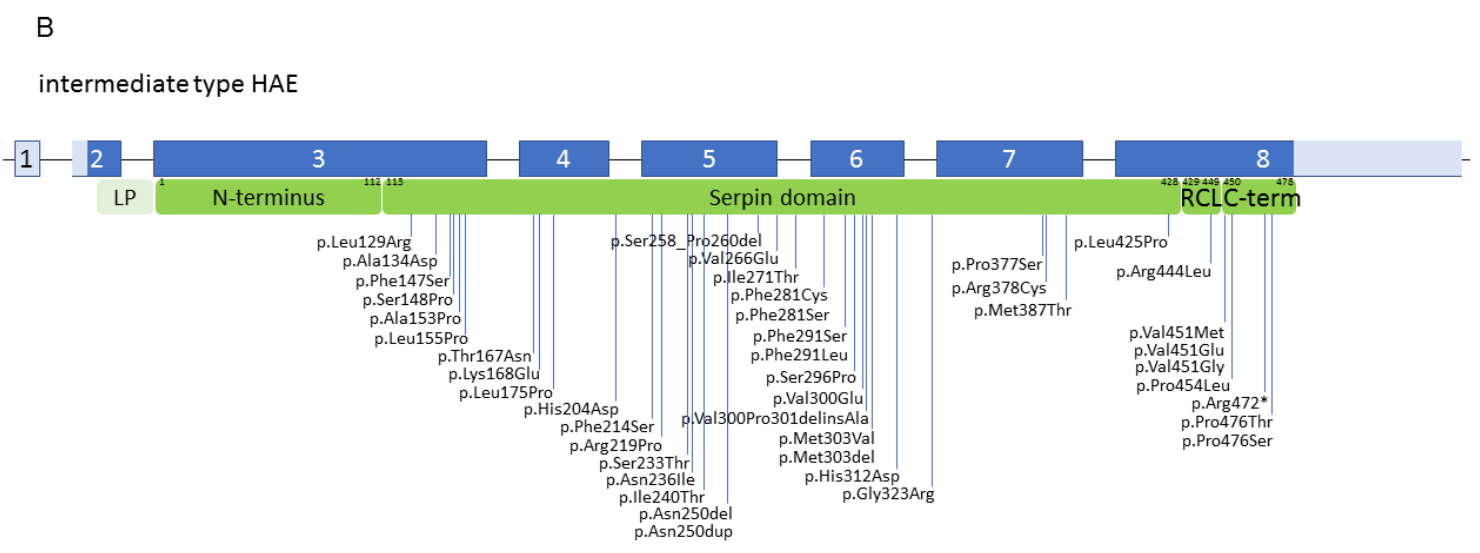

Table 1. Variants associated with type-II and intermediate-type hereditary angioedema phenotypes. Fifty-five SERPING1 variants categorised into Class I (noninhibitory C1Inh with altered exposure of the active site), Class II (disturbed insertion of the reactive centre loop, RCL, to properly develop Serpin-protease associations) and Class III (spontaneous self or mutual insertion of the RCL). For more detailed explanation, see Bos et al., [2002]; Beinrohr et al., [2007]. The results from three bioinformatic methods applied to missense substitutions of interest for structure are summarised: SIFT (with score), PolyPhen-2 (with probability score), and MutationTaster (with probability). Location of each of the residues in the Serpin structure is indicated. For an easy reference to the Serpin structure, the variant numbering is given according to the secreted protein sequence.

This article is protected by copyright. All rights reserved. 


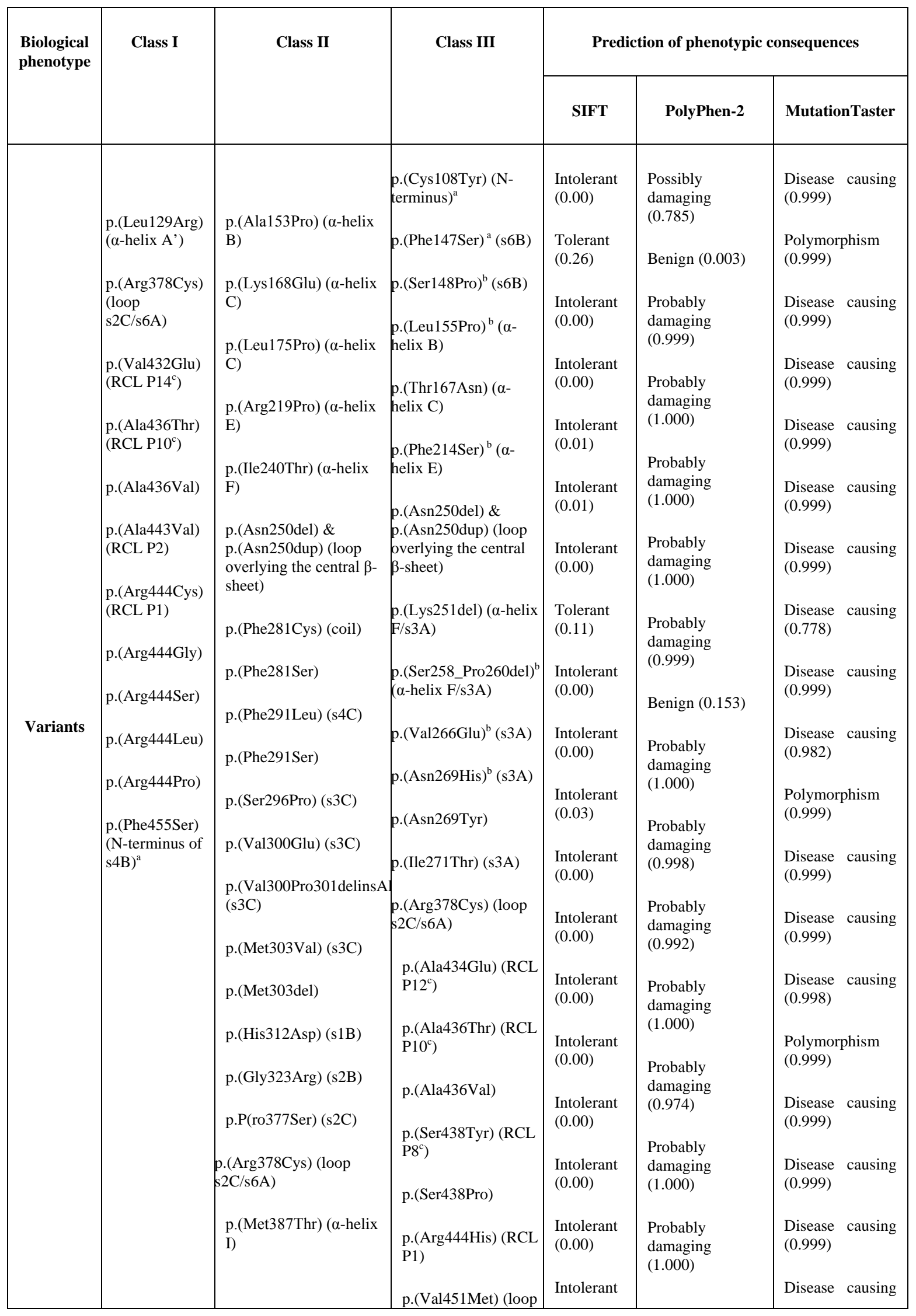

This article is protected by copyright. All rights reserved. 


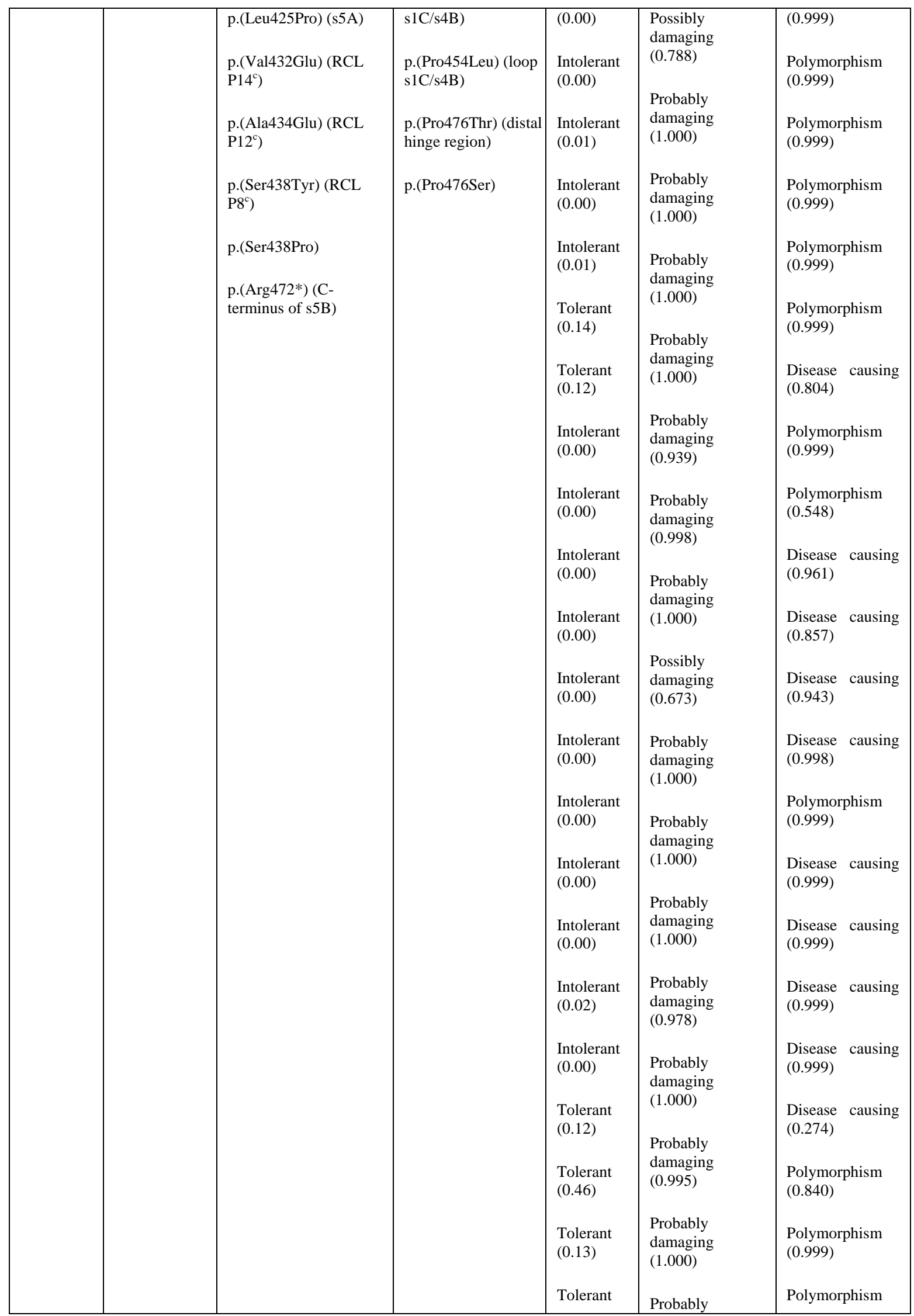

This article is protected by copyright. All rights reserved. 


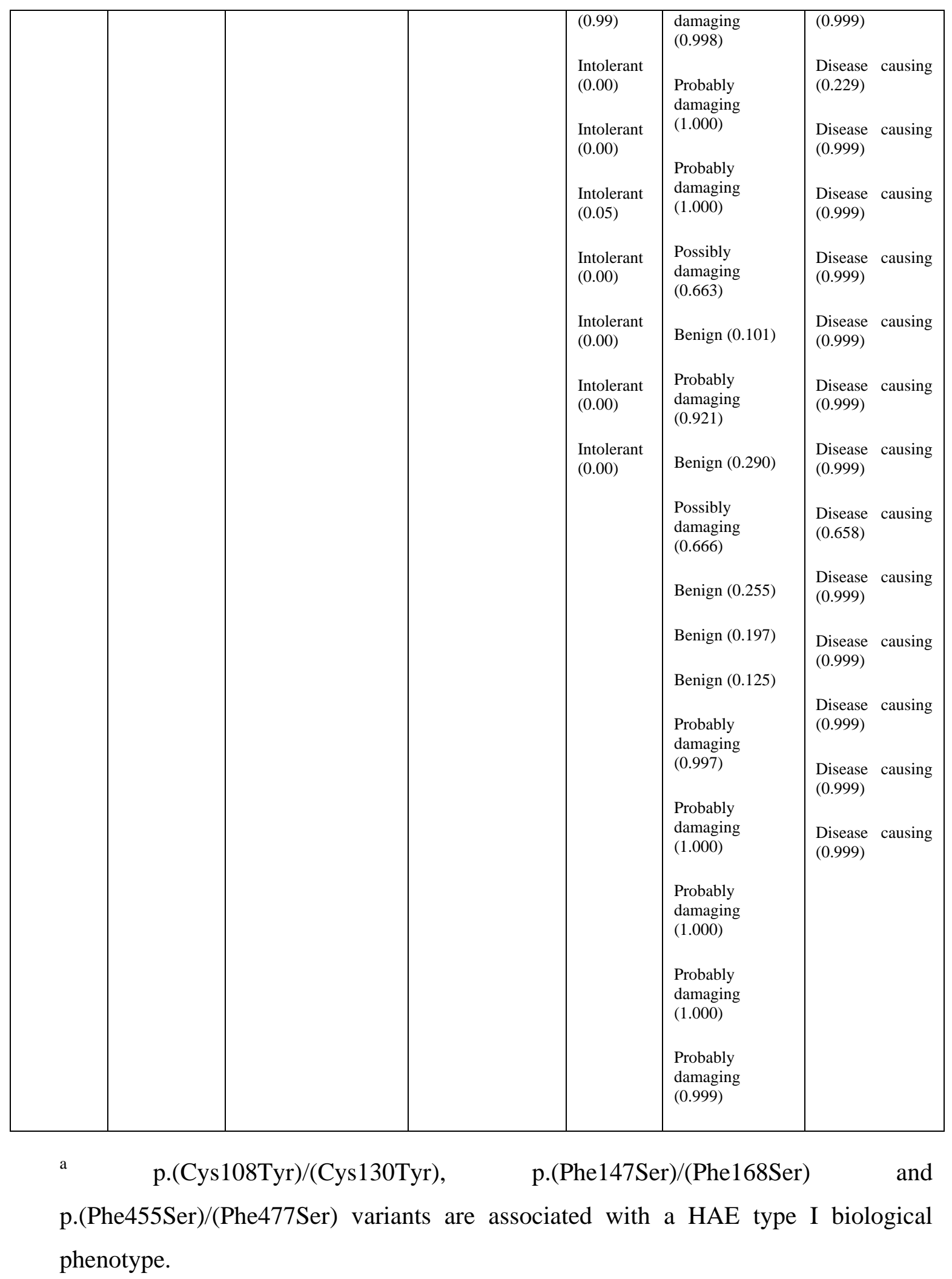

This article is protected by copyright. All rights reserved. 
b p.Ser148Pro/Ser170Pro, p.Leu155Pro/Leu177Pro, p.Phe214Ser/Phe236Ser, p.Val266Glu/Val288Glu and p.Asn269His/Asn291His variants develop a cellular pattern of aggregates with wild-type C1Inh [Haslund et al., 2018] and are associated with a HAE-I or a HAE-intermediate biological phenotype

${ }^{\text {c }}$ P8, P10, P12 and P14 are referring to Stein \& Carrell [1995], where position Ala ${ }^{434}$ of C1Inh attributed to P12 is supposed to be homologous to $\mathrm{Ala}^{347}$ in $\alpha 1$-antitrypsin, a highly conserved position among serpins.

Table 2. Residue conservation. Variants at conserved amino acid positions in Serpin sequences. SERPING1 gene variants, incl those described in supporting information Tables 1 and 2, distributed in strictly conserved positions among Serpin sequences. Possible intramolecular interactions in native or latent wild-type C1Inh between conserved residues have been suggested taking $\alpha 1$-antitrypsin as the reference Serpin. For an easy reference to Serpin structure and to Serpin sequence alignments, the variant numbering is given according to the secreted protein sequence of C1Inh and A1AT.

\begin{tabular}{|c|c|c|c|c|}
\hline $\begin{array}{l}\text { C1 Inh } \\
\text { residue }^{\mathrm{a}}\end{array}$ & $\begin{array}{l}\text { Naturally } \\
\text { occurring } \\
\text { variant }\end{array}$ & $\begin{array}{l}\text { Consensus } \\
\text { residue }\end{array}$ & $\begin{array}{l}\text { Location } \\
\text { in Serpin } \\
\text { structure }\end{array}$ & $\begin{array}{c}\text { Possible interactions of the C1Inh } \\
\text { residue within native Serpin } \\
\text { structure }^{c}\end{array}$ \\
\hline $\mathrm{Phe}^{127}$ & p.(Phe127Val) & Phe (79\%) & helix A & shutter, Phe $^{127}$ packs against \\
\hline $\operatorname{Asn}^{144}$ & p.(Asn144Ile) & Asn (87\%) & $\begin{array}{c}\beta \text {-sheet B } \\
\text { (s1B) }\end{array}$ & shutter/gate, Asn $^{144}$ makes extensive \\
\hline Phe $^{147}$ & p.(Asn144Lys) & Phe (84\%) & (JP) & H-bond network of C1Inh C- \\
\hline Ser $^{148}$ & p.P(he147Ser) & Ser (93\%) & $(\mathrm{s} 6 \mathrm{~B})$ & fermintus (4/4-4/o) \\
\hline Pro $^{149}$ & p.(Ser148Pro) & Pro (90\%) & $\beta$-sheet B & $\begin{array}{l}\text { shutter; p.(Phe147Ser) variant is } \\
\text { likely to destabilise the closure of a }\end{array}$ \\
\hline Leu $^{156}$ & p.(Ser148Phe) & Leu (75\%) & (s6B) & $\begin{array}{l}\text { five-stranded central } \beta \text {-sheet, which } \\
\text { in turn favors oligomerisation; }\end{array}$ \\
\hline Gly $^{162}$ & p.(Pro149Gln) & Gly (80\%) & terminus & $\begin{array}{lll}\text { apparent } & \text { correspondence } & \text { to } \\
\text { p.(Phe52del) Mmalton in A1AT }\end{array}$ \\
\hline $\operatorname{Thr}^{167}$ & p.(Pro149Leu) & Thr (87\%) & & shutter, Ser148Pro develops cell \\
\hline
\end{tabular}

This article is protected by copyright. All rights reserved. 


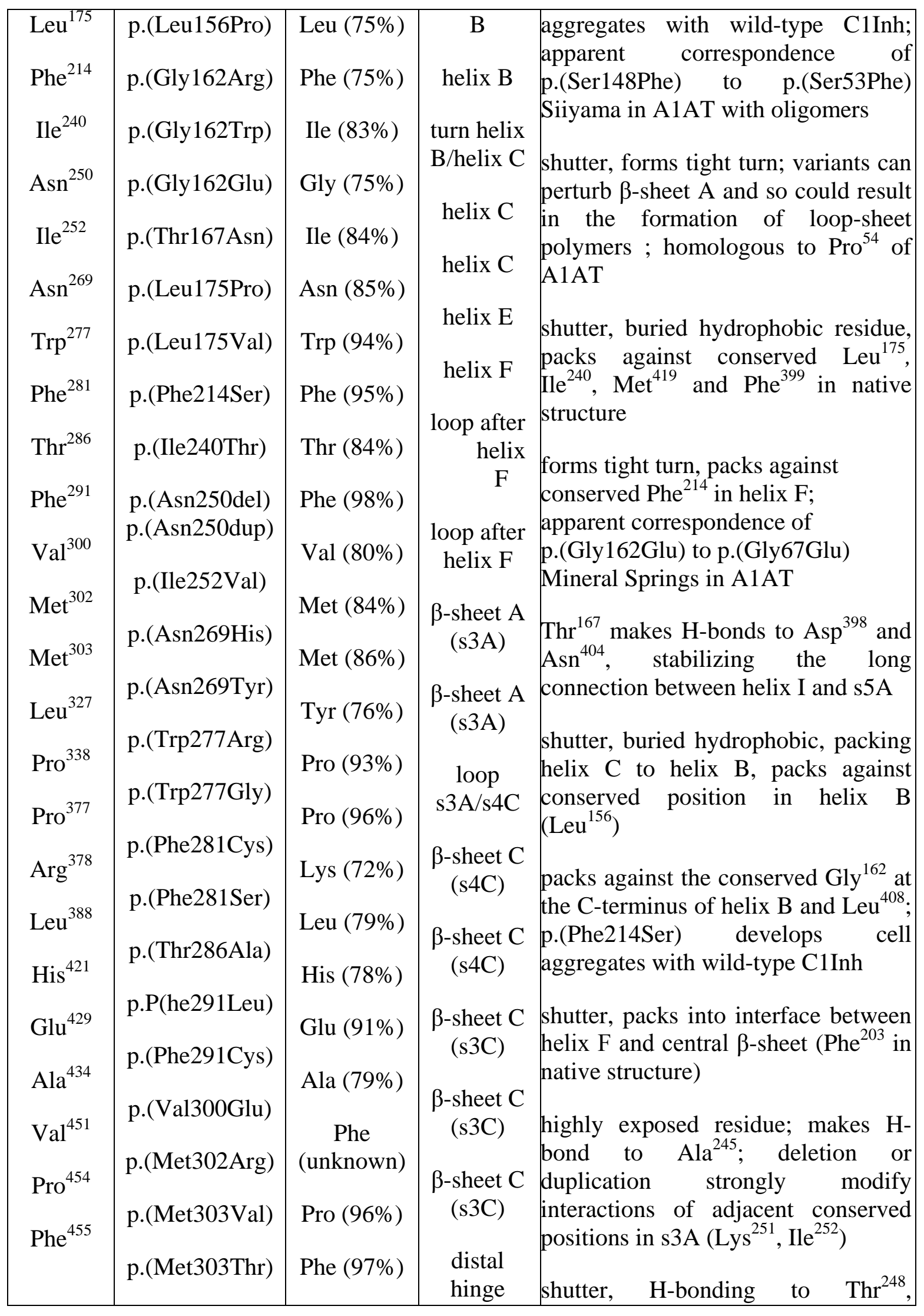

This article is protected by copyright. All rights reserved. 


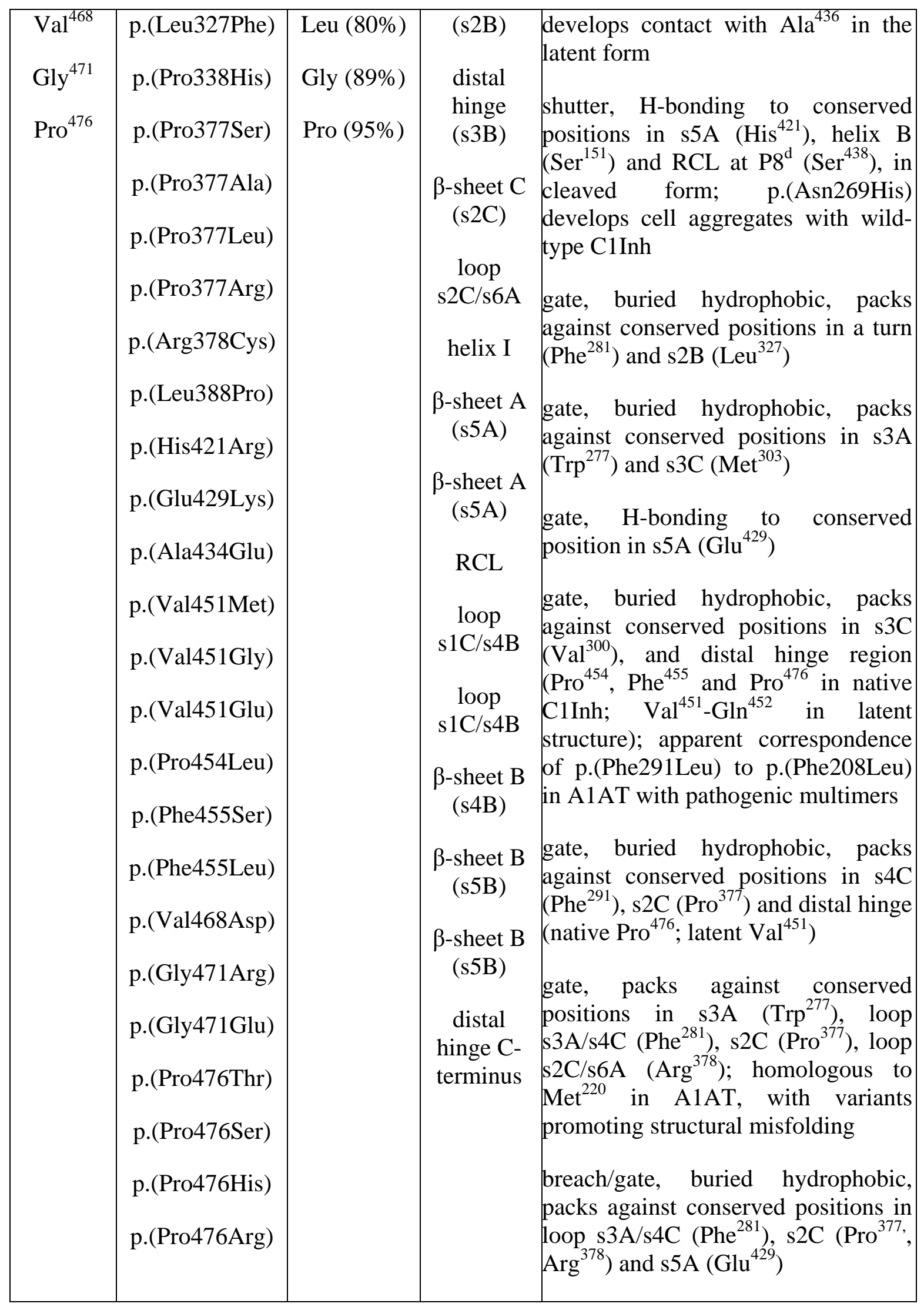

This article is protected by copyright. All rights reserved. 


\begin{tabular}{|c|c|}
\hline p.(Pro476Leu) & 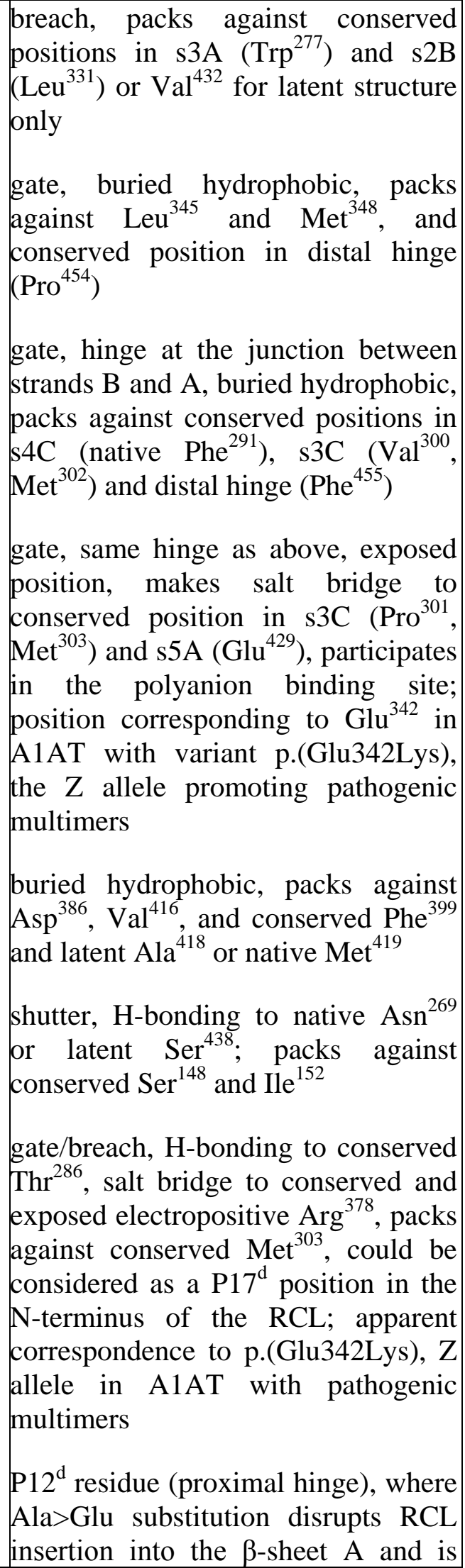 \\
\hline
\end{tabular}

This article is protected by copyright. All rights reserved. 


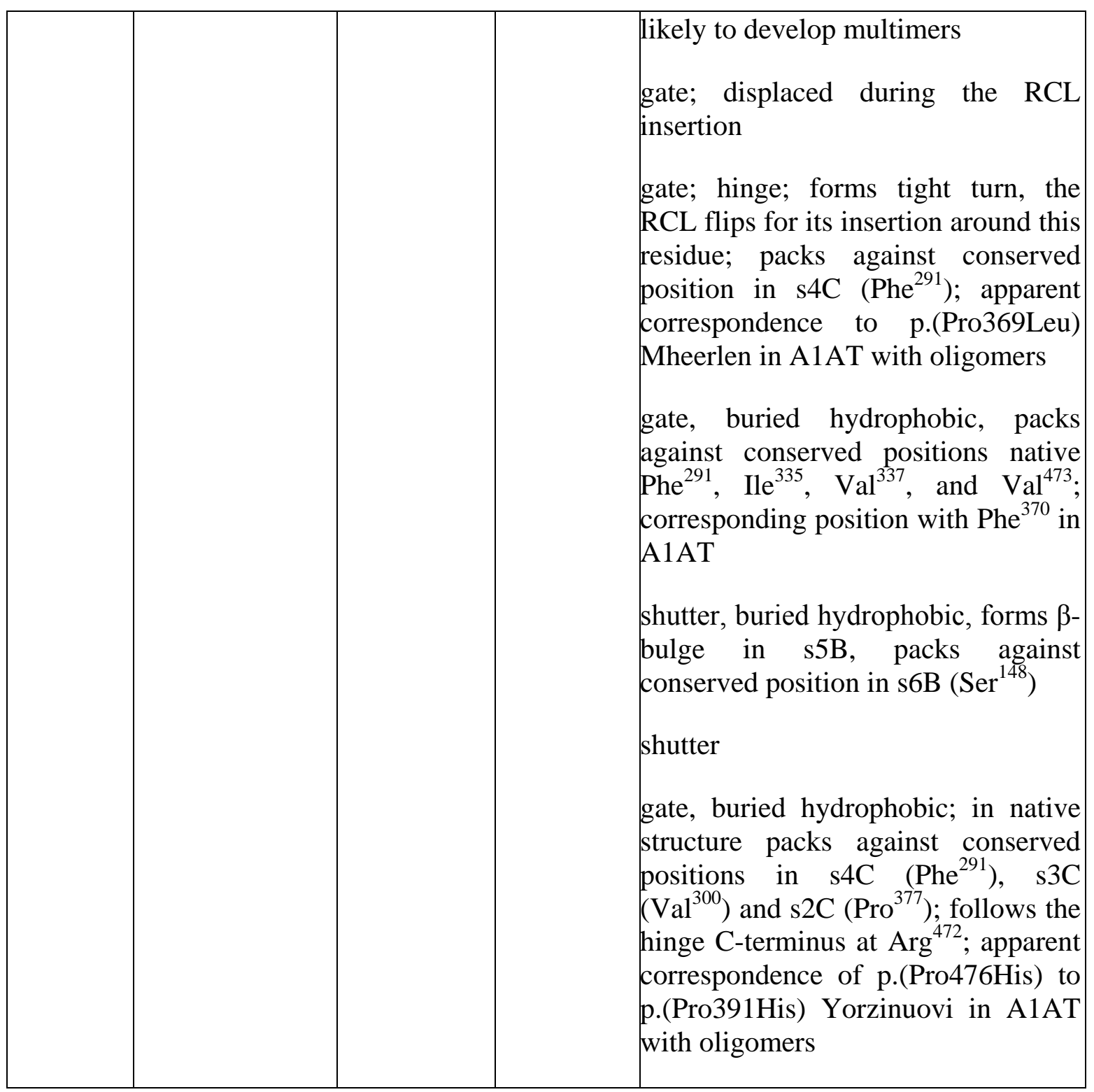

${ }^{a}$ Position numbering omitting signal peptide, according to indications in structural models (PDB entries 5DU3 and 2OAY).

${ }^{\mathrm{b}}$ High residue conservation (>70\%) between aligned sequences of 219 Serpins, with the numbers in brackets indicating the percentage of shares [Irving et al., 2000].

${ }^{\mathrm{C}}$ Interactions described based on those reported for the human native C1 Inhibitor (PDB entry 5DU3), or latent C1Inh (PDB entry 2OAY). The functional strategic breach, shutter, gate and other structure features are indicated in Fig 1B.

This article is protected by copyright. All rights reserved. 
${ }^{\mathrm{d}}$ P8, P12 and P17 are referring to Stein \& Carrell [1995], where position Ala ${ }^{434}$ of C1Inh attributed to P12 is supposed to be homologous to $\mathrm{Ala}^{347}$ in A1AT.

A1AT, $\alpha 1$-antitrypsin

This article is protected by copyright. All rights reserved. 